\title{
HIGH RELIABILITY SHEATHED, BERYLLIA INSULATED, TUNGSTEN-RHENIUM ALLOY THERMOCOUPLE ASSEMBLIES - THEIR FABRICATION AND EMF STABILITY
}

\author{
by \\ G. W. Burns, W. S. Hurst and M. G. Scroger
}

prepared for

NATIONAL AERONAUTICS AND SPACE ADMINISTRATION

INTERAGENCY AGREEMENT

NASA ORDER NO. C-61545-B 


\section{NOTICE}

This report was prepared as an account of Government sponsored work. Neither the United States, nor the National Aeronautics and Space Administration (NASA), nor any person acting on behalf of NASA:

A.) Makes any warranty or representation, expressed or implied, with respect to the accuracy, completeness, or usefulness of the information contained in this report, or that the use of any information, apparatus, method, or process disclosed in this report may not infringe privately owned rights; or

B.) Assumes any liabilities with respect to the use of, or for damages resulting from the use of any information, apparatus, method or process disclosed in this report.

As used above, "person acting on behalf of NASA" includes any employee or contractor of NASA, or employee of such contractor, to the extent that such employee or contractor of NASA, or employee of such contractor prepares, disseminates, or provides access to, any information pursuant to his employment or contract with NASA, or his employment with such contractor. 


\begin{tabular}{|c|c|}
\hline $\begin{array}{l}\text { 1. Report No. } \\
\text { INASA CR-134549 }\end{array}$ & 3. Recipient's Catalog No. \\
\hline $\begin{array}{l}\text { 4. Title and Subtitle } \\
\text { HIGH RELIABILITY SHEATHED, BERYLLIA INSULATED, TUNGSTEN-RHENIUM } \\
\text { ALLOY THERMOCOUPLE ASSEMBLIES - THEIR FABRICATION AND EMF } \\
\text { STABILITY }\end{array}$ & $\begin{array}{l}\text { 5. Report Date } \\
\text { June, } 1974 \\
6 . \text { Performing Organization Code }\end{array}$ \\
\hline $\begin{array}{l}\text { 7. Author(s) } \\
\text { G. W. Burns, W. S. Hurst, and M. G. Scroger }\end{array}$ & $\begin{array}{l}\text { 8. Performing Organization Report No. } \\
\text { NBSIR } 74-447\end{array}$ \\
\hline \multirow{3}{*}{$\begin{array}{l}\text { 9. Performing Organization Name and Address } \\
\text { U. S. Department of Commerce } \\
\text { National Bureau of Standards } \\
\text { Institute for Basic Standards } \\
\text { Washington, D. C. } 20234\end{array}$} & 10. Work Unit No. \\
\hline & $\begin{array}{l}\text { 11. Contract or Grant No. } \\
\text { C-61545-B }\end{array}$ \\
\hline & 13. Type of Report and Period Covered \\
\hline \multirow{2}{*}{$\begin{array}{l}\text { 12. Sponsoring Agency Name and Address } \\
\text { National Aeronautics and Space Administration } \\
\text { Washington, D. C. } 20546\end{array}$} & \\
\hline & 14. Sponsoring Agency Code \\
\hline
\end{tabular}

15. Supplementary Notes

Project Manager, I. Warshawsky, Instrument Consultant, Physical Science Division, National Aeronautics and Space Administration, Lewis Research Center, Cleveland, Ohio, and G. E. Glawe, Technical Monitor

16. Abstract

$1.6 \mathrm{~mm}$ diameter tantalum sheathed, BeO insulated, $\mathrm{W}-3 \% \mathrm{Re} / \mathrm{W}-25 \%$ Re thermocouple assemblies have been fabricated and their emf drift determined during 2059 hours of exposure at $2073 \mathrm{~K}$ in a gaseous helium environment. The sheathed thermocouple assemblies were constructed from aged thermoelements, specially heat-treated BeO insulators, and specially cleaned and etched tantalum sheaths. Their thermal emf drifts ranged from the equivalent of only -0.3 to $-0.8 \mathrm{~K} \mathrm{drift}$ per 1000 hours of exposure at $2073 \mathrm{~K}$. No evidence of any gross chemical attack or degradation of the component materials was found. The emf drift and material behavior of some unsheathed, Beo insulated, $\mathrm{W}-3 \% \mathrm{Re} / \mathrm{W}-25 \%$ Re thermocouples at 2250 and $2400 \mathrm{~K}$ were also determined. Unsheathed thermocouples tested in an argon environment at $2250 \mathrm{~K}$ for 1100 hours and at $2400 \mathrm{~K}$ for $307 \mathrm{hours}$ exhibited changes in thermal emf that typically ranged from the equivalent of a few degrees $K$ to as much as $+11 \mathrm{~K}$. Post-test examinations of these thermocouples revealed some undesirable material degradation and interaction which included erosion of the BeO insulators and contamination of the thermoelements by tantalum from the tantalum blackbody enclosure in which the thermocouples were contained. Preliminary tests to examine the chemical compatibility of sintered BeO insulators with $\mathrm{Ta}$ sheaths in an argon environment at 2073, 2250, and $2400 \mathrm{~K}$ Were also conducted. They revealed gross erosion of the insulator after only 50 hours exposure at $2400 \mathrm{~K}$. A $50 \%$ reduction in the insulator diameter at the open end of the sheath was typical. Well inside the sheath, where gaseous reaction products were confined, the erosion was considerably less. Similar behavior occurred with long exposure (1100 hours) at $2250 \mathrm{~K}$. Serious problems with the BeO insulators were not apparent in tests at $2073 \mathrm{~K}$.

\begin{tabular}{|l|l|l|l|}
\hline 17. Key Words (Suggested by Author(s)) & 18. Distribution Statement \\
Beryllium Oxide & & Unclassified - UnIimited \\
$\begin{array}{l}\text { Emf Drift } \\
\text { Sheathed Thermocouples } \\
\text { Tantalum } \\
\text { Temperature Measurements } \\
\text { Tungsten-Rhenium Alloys }\end{array}$ & 20. Security Classif. (of this page) & 21. No. of Pages & 22. Price* \\
\hline $\begin{array}{l}\text { 19. Security Classif. lof this report) } \\
\text { Unclassified }\end{array}$ & 36 & 3.00 \\
\hline
\end{tabular}

*For sale by the National Technical Information Service, Springfield, Virginia 22151 
SUMMARY

INTRODUCTION

EXPERIMENTAL PROCELURES AND APPARATUS . . . . . . . . . . . . . . . . . . . 3

DRIFT TEST WITH SHEATHED THERMOCOUPLE ASSEMBLIES . . . . . . . . . . . . 3

Preparatory heat treatments and chemical cleaning of materials . . . . . 3

Eabrication and installation of the thermocouple assemblies . . . . . . . 3

Initiation of the drift test and test procedures. . . . . . . . . . . 4

DRIFT TESTS WITH UNSHEATHED THERMOCOUPLE ASSEMBLIES. . . . . . . . . . . . 6

COMPATIBILITY STUDIES OF BeO INSULATORS WITH TANTALUM SHEATHS. . . . . . . . . . 6

MATERIALS TESTED. . . . . . . . . . . . . . . . . . . . . . . . 6

EXPERIMENTAL RESULTS AND DISCUSSION . . . . . . . . . . . . . . . . . 7

TESTS WITH SHEATHED THERMOCOUPLE ASSEMBLIES. . . . . . . . . . . . . 7

Thermal emf drift . . . . . . . . . . . . . . . . . 7

Post-test examination of materials. . . . . . . . . . . . . . . . . 14

TESTS OF UNSHEATHED BeO-INSUlATED THERMOCOUPLES. . . . . . . . . . . . . 22

Thermál emf drift . . . . . . . . . . . . . . . . . 22

Material behavior . . . . . . . . . . . . . . . . . . 22

STUdIES OF BeO-Ta SHEATH COMPATIBILITY . . . . . . . . . . . . . . . . 29

CONCLUDING REMARKS. . . . . . . . . . . . . . . . . . . . . 32

BeO-Ta COMPATIBILITY Tests . . . . . . . . . . . . . . . . . . 32

TESTS WITH UNSHEATHED BeO-INSULATED THERMOCOUPLES. . . . . . . . . . . . . 34

TESTS WITH SHEATHED THERMOCOUPLE ASSEMBLIES. . . . . . . . . . . . . . . 34

REFERENCES. . . . . . . . . . . . . . . . . . . . . . 36 
HIGH RELIABILITY SHEATHED, BERYLLIA INSULATED,

TUNGSTEN-RHENIUM ALLOY THERMOCOUPLE ASSEMBLIES-

THEIR FABRICATION AND EMF STAEILITY

by

G. W. Burns, W. S. Hurst, and M. G. Scroger

National Bureau of Standards

Temperature Section

SUMMARY

This report presents information on the fabrication and the performance of $1.6 \mathrm{~mm}$ diameter tantalum sheathed, beryllium oxide (BeO) insulated, $\mathrm{W}-3 \%$ Re vs $\mathrm{W}-25 \%$ Re thermocouple assemblies. The thermocouple assemblies were tested at $2073 \mathrm{~K}$ for 2059 hours. Tests were also performed with unsheathed, BeO insulated $\mathrm{W}-3 \%$ Re vs $\mathrm{W}-25 \%$ Re thermocouples. These thermocouples were exposed at 2250 and $2400 \mathrm{~K}$ for periods up to 1100 hours. In addition, studies of the chemical compatibility of sintered BeO insulators with tantalum sheaths at 2073, 2250, and $2400 \mathrm{~K}$ are also presented. A11 of the investigations were conducted in gaseous environments of high purity argon or helium at a pressure of nominally $1 \mathrm{~atm}$. Material characterization included metallographic examination and chemical analyses both before and after the high temperature exposures.

The sheathed thermocouple assemblies were constructed from aged $\mathrm{W}-3 \% \operatorname{Re}$ and $\mathrm{W}-25 \% \operatorname{Re}$ thermoelements, specially heat treated sintered BeO insulators, and specially cleaned and etched tantalum sheaths. Four such assemblies were constructed. After evacuating, baking, and helium leak testing the assemblies, they were filled with high purity argon gas and hermetically sealed. The thermal emf drift of the assemblies was then determined during an exposure in a gaseous helium environment at $2073 \mathrm{~K}$ for 2059 hours. The measured thermal emf drifts were smaller than the estimated measurement uncertainties and ranged from the equivalent of only 0.3 to $0.8 \mathrm{~K}$ downward drift per 1000 hours of exposure at $2073 \mathrm{~K}$. Rapid cooling (at a rate of about $400 \mathrm{~K} /$ min during the first 2 minutes) of the thermocouple assemblies to room temperature after exposure for 88, 252, 553, and 1680 hours did not appreciably alter their values of thermal emf at $2073 \mathrm{~K}$. Post test examinations of the component materials revealed no evidence of any gross chemical attack. However, some minor contamination at the surface of the thermoelements was observed along those portions that were in a steep temperature gradient during the test.

The unsheathed, BeO insulated $\mathrm{W}-3 \%$ Re vs $\mathrm{W}-25 \%$ Re thermocouples were tested in argon at $2250 \mathrm{~K}$ for 1100 hours and at $2400 \mathrm{~K}$ for 307 hours. Their values of thermal emf at the test temperature typically increased by the equivalent of a few degrees $\mathrm{K}$ to as much as $11 \mathrm{~K}$. While these changes are small, they nevertheless are substantially larger than the changes observed in the test of the sheathed thermocouple assemblies. The unsheathed thermocouples exhibited undesirable material degradation and interaction effects in both tests. These effects included erosion and a reduction in the diameter of BeO insulators in the hot-zone of the furnace, coatings of tantalum on bared portions of the thermoelements, coatings of beryllium on the BeO insulators in the temperature-gradient zone of the furnace and microcracking of the BeO insulators in cases where the exposure temperature exceeded the phase transformation temperature of the BeO.

Studies of the chemical compatibility of the BeO insulators with the tantalum sheaths were performed by exposing open-ended tantalum sheaths that contained a specimen of BeO tubing. Tests were run at 2073, 2250, and $2400 \mathrm{~K}$ in an argon environment. Gross erosion of the BeO insulator occurred with only 50 hours exposure at $2400 \mathrm{~K}$, particularly at the open end of the sheath (greater than $50 \%$ erosion was typical). Erosion was markedly less inside the sheath, where the gaseous reaction products were confined. Microcracking of 
the BeO also occurred. With 1100 hours of exposure at $2250 \mathrm{~K}$ similar erosion of the BeO was observed but no microcracking was evident. Serious problems with the BeO were not apparent in tests at $2073 \mathrm{~K}$. At this temperature the BeO insulators exhibited shrinkage of about 10 percent in diameter. This was also observed in earlier tests (ref. 1) in which $\mathrm{BeO}$ insulators were exposed to high temperatures in the presence of tantalum. The shrinkage results from further densification of the sintered insulator and is accompanied by a reduction in the impurity level.

\section{INTRODUCTION}

This report presents results of a continuing study (refs. 2 and 3), which has been directed towards improving the general reliability of metal-sheathed, ceramic-insulated, W-Re type thermocouple sensors. Reliable sensor operation for prolonged periods of time (for many thousands of hours) at temperatures above $1800 \mathrm{~K}$ has been of primary concern. Useful criteria have been sought regarding the selection, preparation, and performance of materials that might be applied in the design and construction of suitable sensors.

Previous studies were concerned with the behavior of bare (non-insulated) commercially available W-Re alloy thermoelements and with the behavior of these thermoelements when fabricated as a thermocouple and insulated with high purity BeO. In the initial studies (ref. 4) $0.25 \mathrm{~mm}$ diameter $\mathrm{W}-3 \%$ Re and $\mathrm{W}-25 \%$ Re thermoelements were exposed at temperatures of 2200 to $2600 \mathrm{~K}$ in environments of high purity argon or hydrogen (nominally $1 \mathrm{~atm}$ pressure) or in high vacuum of less than $1.3 \times 10^{-6} \mathrm{~Pa}\left(1 \times 10^{-8} \text { torr }\right)^{1}$ for periods up to 1000 hours. With exposure in the gaseous environments, initial changes ${ }^{2}$ (shifts) in the emf-temperature relationship of the thermoelements were found to occur usually within 50 hours or less of exposure ${ }^{3}$. With continued high temperature exposure of the thermoelements in the gaseous environments, the subsequent long term changes (drift) in the emf-temperature relationship were negligible. Conventional metallographic and chemical analyses were performed to more fully characterize the thermoelements. The thermoelements exposed in vacuum at temperatures above $2200 \mathrm{~K}$ exhibited a continual drift in their emf-temperature relationship as a result of the preferential evaporation of $\mathrm{Re}$.

Subsequent work (ref. 1) extended the bare-wire studies to include other commercially available W-Re alloy thermoelements. Iarameters for aging were developed that would minimize the initial shift in the thermal emf and yet leave the thermoelements with sufficient room temperature ductility to permit subsequent fabrication of thermocouple sensors. In addition, studies were initiated to examine the behavior of thermoelements and thermocouples when insulated with high purity sintered BeO tubing. W- $3 \% \operatorname{Re}$ vs $\mathrm{W}-25 \% \operatorname{Re}$ thermocouples, fabricated from thermally aged thermoelements and insulated with well degassed sintered BeO tubing, exhibited drifts of only 2 to $3 \mathrm{~K}$ during exposure in argon at $2073 \mathrm{~K}$ for 1029 hours.

11 torr $=\left(1.01325 \times 10^{5} / 760\right) \mathrm{Pa}$. All values of pressure are indicated equivalent nitrogen pressures.

2

The change in the emf-temperature relationship of a thermoelement is defined as the emf-temperature relationship of a thermocouple that is comprised of that thermoelement versus an unheated "as received" thermoelement from the same spool (lot) of wire, when the reference junctions are maintained at $273.15 \mathrm{~K}$ and the unheated "as received" thermoelement is designated as the negative leg of the thermocouple.

3

Efforts to minimize the shift have been reported. See for example, Tseng et a1., ref. 8. 
This work presents further studies of the thermoelectric stability of Be0-insulated $\mathrm{W}-3 \% \operatorname{Re}$ versus $\mathrm{W}-25 \%$ Re thermocouples during exposure in argon at $2250 \mathrm{~K}$ for 1100 hours and at $2400 \mathrm{~K}$ for 307 hours. Studies of the compatibility of BeO with Ta sheaths at 2073, 2250 and $2400 \mathrm{~K}$ are presented. Finally, using carefully prepared and cleaned materials, Ta sheathed, BeO insulated $\mathrm{W}-3 \%$ Re vs $\mathrm{W}-25 \%$ Re thermocouples were fabricated and tested in helium at $2073 \mathrm{~K}$ for 2059 hours. The thermal emf test results and the post-test analyses of the component materials are presented.

\section{EXPERIMENTAL PROCEDURES AND APPARATUS}

\section{DRIFT TEST WITH SHEATHED THERMOCOUPLE ASSEMBLIES}

Preparatory heat treatments and chemical cleaning of materials. Four $1.6 \mathrm{~mm}$ diameter tantalum sheathed, Be0-insulated, $\mathrm{W}-3 \%$ Re versus $\mathrm{W}-25 \%$ Re thermocouple assemblies were fabricated for testing at $2073 \mathrm{~K}$. Prior to the fabrication, the component materials were subjected to preparatory heat treatments and cleaning procedures.

The thermoelements were cleaned with ether and then heated for about 1 hour at $1570 \mathrm{~K}$ in vacuum $\left(<5 \times 10^{-8} \text { torr }\right)^{4}$, using test chambers described previously (refs. 2 and 4). This was followed by aging at $2400 \mathrm{~K}$ in high purity argon ( $<10 \mathrm{ppm}$ total impurities) in order to essentially remove the initial emf shift (refs. 1 and 3 ). The W- $3 \%$ Re thermoelements were aged for 1 hour and the $\mathrm{W}-25 \%$ Re thermoelements were aged for 10 minutes.

The BeO insulators were vacuum degassed in an ultra-high-vacuum (UHV), high temperature furnace. The furnace, described previously, employs a tungsten wire mesh heating element, tungsten radiation shields and a copper cold wall, and is pumped with an ion pump and an optional titanium sublimation pump (refs. 1 and 2). For the degas, the BeO insulators were suspended in the $30 \mathrm{~cm}$ long hot-zone of the furnace in a W-Re basket. The furnace temperature was increased to about $1525 \mathrm{~K}$ and held for about 12 hours, and then increased to about $1700 \mathrm{~K}$ where it was held for 9 hours. The pressure in the furnace was maintained at less than $5 \times 10^{-7}$ torr by continuous pumping during the degas.

The tantalum sheaths were cut to approximately the desired length with a $0.15 \mathrm{~mm}$ thick $\mathrm{Al}_{2} \mathrm{O}_{3}$ cut-off wheel. The sheat.s were rinsed in methanol and trichloroethylene, and then etched for about 2.5 minutes in a solution of $33 \% \mathrm{HNO}_{3}, 33 \% \mathrm{HF}$ and $33 \% 1$ actic acid. Following the acid etch, the sheaths were rinsed for 5 minutes in tap water and then rinsed again in the above solvents. The sheaths were cut to final size (about $29 \mathrm{~cm}$ long) by cutting off one end with a tube cutter that had a hardened steel cutting wheel and was modified so that its steel rolling surfaces were replaced with a strip of Ta. The cut end of the sheath that was partially closed by the tube cutter was then welded closed with a tungsten inert gas welder under cover of argon gas. The sheaths were then put in a Ta holder and placed in the UHV furnace for vacuum degassing. For degassing, the furnace temperature was increased slowly over a period of 10 hours to about $1875 \mathrm{~K}$, held at this temperature for about 16 hours and then increased to about $2175 \mathrm{~K}$ where it was maintained for about 1 hour. The furnace was then cooled in steps to room temperature in about 2 hours. During the degas, the pressure was maintained at less than $5 \times 10^{-7}$ torr.

Fabrication and installation of the thermocouple assemblies. Following the heat treatments of the component materials, the components were stored in a vacuum until the construction of the thermocouple assemblies was undertaken. For assembly, the measuring junctions of the four thermocouples were formed by welding with a dc arc in a helium atmosphere. The double-bore $\mathrm{BeO}$ insulators were then gently slid onto the thermoelements and the thermocouples were slipped into the tantalum sheaths until the measuring junctions were approximately $5 \mathrm{~mm}$ from the closed-end of the sheath. All material handling was done with polyethylene gloves and chemically-cleaned tools.

4 torr $=\left(1.01325 \times 10^{5} / 760\right) \mathrm{Pa}$. All values of pressure are indicated equivalent nitrogen pressures. 
The four tantalum sheathed thermocouple assemblies were installed in a tantalum blackbody enclosure that was suspended in the hot-zone of the UHV high-temperature furnace as shown in Fig. 1. The apparatus is designed so that, after testing, the blackbody and top radiation shield pack can be removed along with the $15 \mathrm{~cm}$ diameter top access flange in such a manner as to not load any of the sheaths. Dismantling of the sheaths after testing can then be done outside of the furnace in as non-destructive a manner as possible. The blackbody enclosure closely approximates an ideal blackbody if the walls of the enclosure are at a uniform temperature. Using calculations derived by DeVos (ref. 5), it is estimated that the effective emittance of the enclosure is greater than 0.995 .

The mounting of the sheath into the stainless steel access flange is shown in Fig. 1. Underneath the flange, the $\mathrm{Ta}$ sheath is held in a stainless steel three-piece compression type fitting. A $0.15 \mathrm{~mm}$ thick gold o-ring is inserted into the fitting and provides the primary vacuum seal at the end of the Ta sheath. The stainless steel tee mounted on the top of the flange is an UHV coupling that employs copper gaskets. The thermoelements are brought out through a Kovar-seal header, and the thermoelements are sealed with a solventfree epoxy resin to the Kovar feedthrough tubes in the header. A connection from each tee is made to a manifold through a $6.3 \mathrm{~mm}$ diameter stainless steel bellows and a stainless steel UHV valve. The manifold is also of stainless steel, of UHV construction, and is equipped with a 200 liter/s ion pump, an ultra-high purity argon gas supply, and a partialpressure analyzer.

Initiation of the drift test and test procedures. After installing the blackbody enclosure with the thermocouple assemblies in the UHV furnace, the furnace and manifold were evacuated and baked for about 10 hours at about $525 \mathrm{~K}$. The thermocouple assemblies were then vacuum degassed in situ: The furnace temperature was increased to about $975 \mathrm{~K}$ over a 3-hour period, held at this temperature for about 22 hours, and then increased to about $1325 \mathrm{~K}$ and held for 2 hours. The pressure in the thermocouple manifold was maintained at less than $2 \times 10^{-7}$ torr during these processes. Following the in situ degas, the thermocouple arsemblies were cooled to room temperature and the furnace chamber was backfilled with helium gas. The thermocouple manifold was backfilled with argon gas. The temperature of the furnace was then slowly increased (over a 4-hour period) to about $2073 \mathrm{~K}$ and stabilized to initiate the drift test. The thermocouples were calibrated against a visual optical pyrometer at about 1195, 1395, 1590 and $1795 \mathrm{~K}$ on bringing them to test temperature. (With the furnace at $2073 \mathrm{~K}$, the pressure in the furnace chamber was about 840 torr and the pressure in the thermocouple manifold was about 780 torr.) The isolation valves to each thermocouple assembly were closed after reaching the test temperature.

During the 2059 hours of test, temperature measurements were made about every 24 hours with an automatic photoelectric optical pyrometer and about every 70 to 100 hours with a visual optical pyrometer (using two observers). Corrections were applied to account for the transmittance of the view port of the furnace. A mechanical shutter was used to shield this view port from the blackbody whenever temperature measurements were not being made. The pyrometers used were of commercial design and were calibrated ${ }^{5}$ by relating the pyrometer lamp current to the brightness or blackbody temperature. In use, the pyrometer lamp current was determined by measuring the voltage drop across a 1 ohm standard resistor in series with the lamp. The reference junctions of the thermocouples were maintained at $273.15 \mathrm{~K}$ in an ice bath during the test. The values of thermal emf were measured with a digital voltmeter (DVM) having an absolute voltage accuracy of $\pm(0.004 \%$ of voltage measured $+2 \mu V)$. The DVM was intercompared with a standard cell and also with a precision potentiometer after every several hundred hours of test. Following procedures similar to those used in previous tests (ref.1), the measured values of emf were adjusted to correspond to a temperature of $2073 \mathrm{~K}$ by making a small correction equivalent to the difference between the temperature determined with the optical pyrometer and $2073 \mathrm{~K}$.

5 Calibration was performed by the Optical Radiation Section of the NBS. 


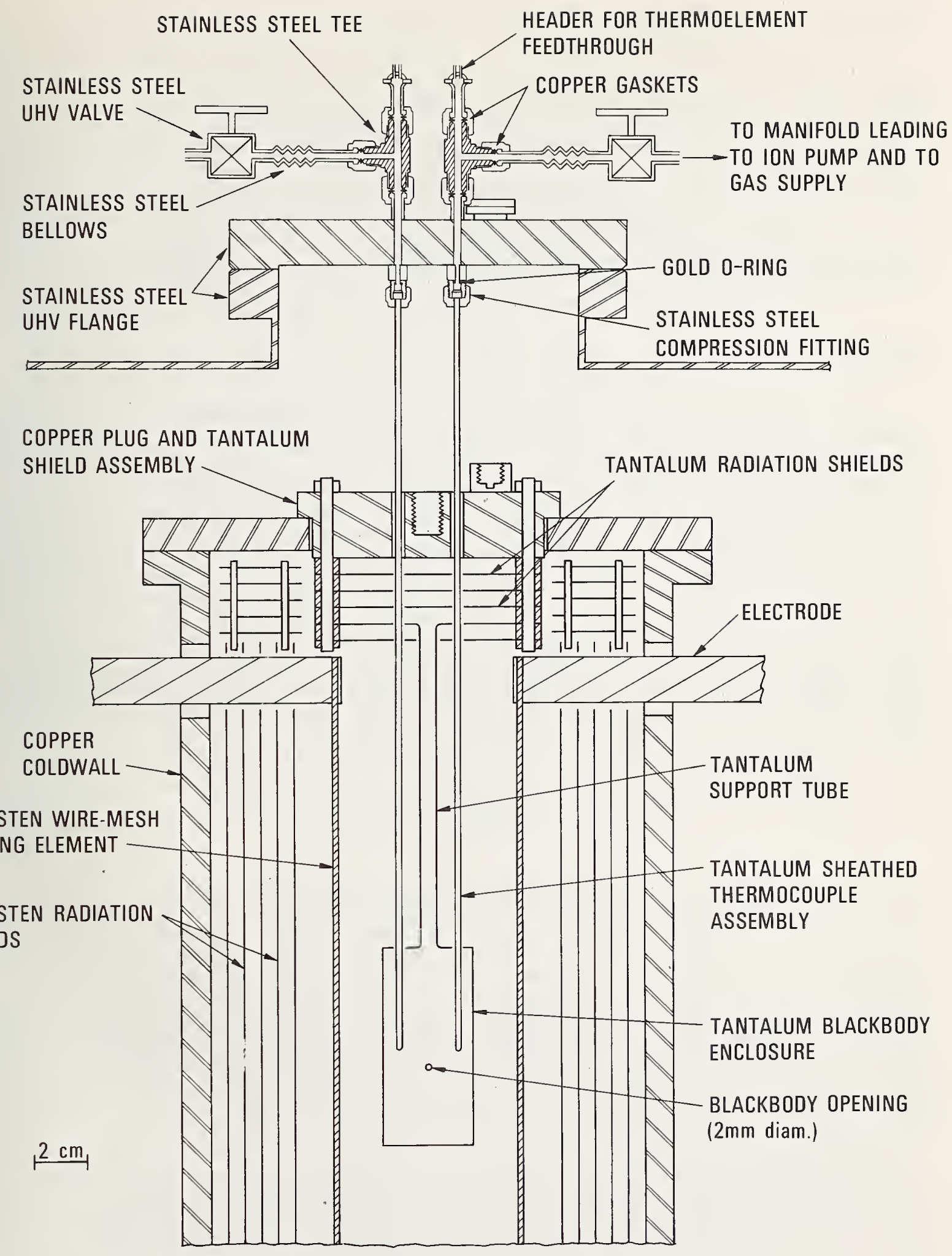

Figure 1. Features of experimental apparatus illustrating the installation of the sheathed thermocouple assemblies for drift testing. Four assemblies were installed. 
Tests were conducted to evaluate the performance of unsheathed BeO-insulated $W-3 \% \operatorname{Re}$ versus $\mathrm{W}-25 \%$ Re thermocouples in argon at temperatures above $2073 \mathrm{~K}$. Test temperatures of 2250 and $2400 \mathrm{~K}$ were employed. The preparation of the W-Re thermoelements and the BeO insulators was the same as that described for the sheathed thermocouple drift test. For the tests, the thermoelements were inserted into the $\mathrm{BeO}$, and the assembly was placed into a tantalum blackbody (similar to that in Fig. 1) so that the measuring junction was within the blackbody enclosure. The insulated thermocouples were inserted into the blackbody enclosure through the $6.35 \mathrm{~mm}$ diameter tantalum supporting tube (as described in more detail in ref. 1). Usually, four thermocouples were inserted into the blackbody. Prior to testing, the thermocouples were vacuum degassed in situ with 2 hour exposures at temperatures of 1000,1100 and $1300 \mathrm{~K}$. The procedure for testing of the thermocouples was very similar to that described for the sheathed thermocouple assemblies in the previous section.

\section{COMPATIBILITY STUDIES OF BeO INSULATORS WITH TANTALUM SHEATHS}

A series of tests were run exposing the BeO insulators contained in the tantalum sheaths to high temperatures. In preparation for these tests, the BeO insulators were degassed in the same manner as that described for the drift tests. The procedures for cleaning and vacuum-degassing of the tantalum sheaths were also similar to that previously described, except that the sheaths were not etched. (Later, similar tests were performed in which etched sheaths were used and virtually identical results were obtained.) Short lengths (typically 5 to $6 \mathrm{~cm}$ ) of the Ta sheathing were cut with the $\mathrm{Al}_{2} \mathrm{O}_{3}$ cut-off wheel, cleaned, vacuum degassed, ard then pinched closed at one end. The degassed BeO insulators were broken into lengths adout $1 \mathrm{~cm}$ longer than the Ta sheaths, and placed in the sheaths. Hence, about $1 \mathrm{~cm}$ of the insulator extended beyond the open end of the sheath. The BeO-Ta sheath assemblies were then strapped with Ta wire on the outside of a Ta blackbody. The blackbody, which was similar to the one shown in Fig. 1, was then placed in the UHV furnace, and the usual bake-out of the furnace and a low temperature degas of the assemblies (at about 1000 to $1300 \mathrm{~K}$ for 3 to 6 hours at pressures of less than $5 \times 10^{-7}$ torr) were performed. After cooling the furnace to ambient temperature, it was back-filled with ultrahigh-purity argon gas in preparation for the high temperature exposure.

\section{MATERIALS TESTED}

The $\mathrm{W}-3 \%$ Re and $\mathrm{W}-25 \%$ Re thermoelements for the tests were taken from a matched lot of thermocouple wire that was obtained from a leading commercial supplier. The thermoelements were nominally $0.25 \mathrm{~mm}$ in diameter. They were given a special surface cleaning treatment by the supplier in order to more thoroughly remove surface contaminants introduced during the manufacturing processes. The cleaning treatment included ultrasonic degreasing, abrading, and electro-etching, and is described in detail by Toenshoff, et al. (ref. 6). The $W-3 \%$ Re thermoelement is an alloy which has been "cioped" by adding small amounts of potassium, silicon, and aluminum compounds to the tungsten oxide prior to its reduction to a metal. The residual doping elements, which remain after the wire forming process, act to produce metallurgical structural changes in the wire when it is exposed to high temperatures that result in improvements in the mechanical properties (ref. 7 ). The $\mathrm{W}-25 \% \operatorname{Re}$ thermoelement is not "doped".

Typical mass spectrographic analyses for specimens from these lots of thermoelements were reported previously (ref. 1). For the W-3\% Re thermoelement the major impurities detected were $\mathrm{K}(100 \mathrm{ppm})$, Mo (100 ppm), and $\mathrm{Fe}(50 \mathrm{ppm})$, while impurities of $\mathrm{Na}, \mathrm{Mg}, \mathrm{Al}$, $\mathrm{Si}, \mathrm{Cl}, \mathrm{Ca}, \mathrm{V}, \mathrm{Cr}, \mathrm{Ni}, \mathrm{Cu}, \mathrm{Ge}$, and $\mathrm{Ta}$ were detected at the 1 to $20 \mathrm{ppm}$ level. For the $\mathrm{W}-25 \% \mathrm{Re}$ thermoelement, Mo $(100 \mathrm{ppm})$ and $\mathrm{Fe}(50 \mathrm{ppm})$ were the major impurities detected, with $\mathrm{Na}, \mathrm{P}, \mathrm{K}, \mathrm{Cr}, \mathrm{Ni}, \mathrm{Ge}$, and $\mathrm{Ta}$ detectable at the 10 to $20 \mathrm{ppm}$ level.

Representative thermocouples from the matched lot of thermocouple wire were calibrated in an argon atmosphere by intercomparison with Pt-Rh type thermocouples in the 673 to $1473 \mathrm{~K}$ range and by intercomparison with an automatic photoelectric optical pyrometer at temperatures to $2400 \mathrm{~K}$. The emf-temperature relationship of the thermocouples, as derived 
from these calibrations, deviated by less than $\pm 1 \%$ from the tabular values of emf and temperature that were reported for the $\mathrm{W}-3 \% \operatorname{Re} v \mathrm{~W}-25 \%$ Re thermocouple by Tseng et al. (ref. 8).

High purity sintered beryllium oxide $(\mathrm{BeO})$ double-bore insulating tubing with $0.3 \mathrm{~mm}$ diam. bores, $1.1 \mathrm{~mm}$ outer diameter and $0.13 \pm 0.03 \mathrm{~mm}$ web size (space between bores) was used in the experiments. All the tubing was from the same production batch and was supplied by the manufacturer in random lengths between 10 and $25 \mathrm{~cm}$ 1ong. Quantitative spectrochemical analyses of representative "as received" samples from this batch of tubing were reported previously (refs. 1 and 3). The major impurities detected were Al (200 to $300 \mathrm{ppm})^{6}, \mathrm{C}(120$ to $230 \mathrm{ppm}), \mathrm{Si}(120$ to $150 \mathrm{ppm}), \mathrm{Mg}(90 \mathrm{ppm})$, and Ca (30 to 50 ppm), while the total detectable impurities (metallic and carbon) were less than $1000 \mathrm{ppm}$. The grain size of the "as received" tubing, as determined from examinations of polished and etched specimens, ranged from about 1 to $5 \mu \mathrm{m}$.

Tantalum tubing with a nominal $1.6 \mathrm{~mm}$ o.d. and $1.3 \mathrm{~mm}$ i.d. was used in the experiments. The tubing was all taken from the same production lot, which was made by a seamless method from electron-beam melted raw material. A variation of about 10 percent was observed in the inner diameter of tubing from this lot. The tubing was supplied by the manufacturer in an as-drawn, straightened, and cleaned condition. The manufacturer reported that the cleaning process consisted of vapor degreasing in hot trichloroethylene after drawing to final size. A typical mass spectrographic analysis of the tantalum tubing is given in the Experimental Results and Discussion section. Niobium (50 ppm) was the principal metallic impurity detected, while other impurities such as $\mathrm{F}, \mathrm{K}, \mathrm{Cu}, \mathrm{Zn}$, and $\mathrm{W}$ were detected at the 1 to $10 \mathrm{ppm}$ level. A report of chemical analysis furnished by the manufacturer of the tantalum tubing indicated carbon at $25 \mathrm{ppm}, \mathrm{O}_{2}$ at $<50 \mathrm{ppm}, \mathrm{H}_{2}$ at $<5 \mathrm{ppm}$ and $\mathrm{N}_{2}$ at $<10 \mathrm{ppm}$.

The argon and helium gases used in the various tests were taken from cylinders of ultra-high purity compressed gas. The gases were certified by the commercial supplier to contain less than $10 \mathrm{ppm}$ by volume total impurities ${ }^{7}$ and within detectable limits this was supported by chemical analyses performed by the Analytical Chemistry Division of the NBS.

Concurrent with these studies, a program was sponsored by NASA for development of commercial thermocouple assemblies. This has been reported by Toenshoff, Zysk and Fleischner (ref. 6). The thermocouples they produced had the same general design as those described in this report. The materials used in both programs were of similar quality.

\section{EXPERIMENTAL RESULTS AND DISCUSSION}

\section{TESTS WITH SHEATHED THERMOCOUPLE ASSEMBLIES}

Thermal emf drift. The thermal emf drift of four $1.6 \mathrm{~mm}$ o.d. tantalum sheathed, BeO insulated, $\mathrm{W}-3 \%$ Re versus $\mathrm{W}-25 \%$ Re thermocouple assemblies was determined during exposure at $2073 \mathrm{~K}$ for 2059 hours in helium ( $1 \mathrm{~atm}$ ). The methods used during the test to obtain the experimental data are discussed in the section on experimental procedures and apparatus.

The four thermocouple assemblies exhibited virtually identical behavior during the test. The values of thermal emf determined for one of the thermocouple assemblies are plotted against time of exposure at $2073 \mathrm{~K}$ in Fig. 2. The data presented are based upon measurements made with the automatic photoelectric optical pyrometer. A straight line is fitted to the data by the method of least squares to show the general trend of the data (the drift). The slope of the line is $-0.013 \mu \mathrm{V} / \mathrm{h}$, which is equivalent to about $-0.8 \mathrm{~K}$ per 1000 hours. While some systematic variation of the data points about the straight line is

6 The values in parentheses give the range in the composition of the element in parts per million by weight as determined from analyses of several specimens.

7

This assumes the helium gas to be free of neon. 


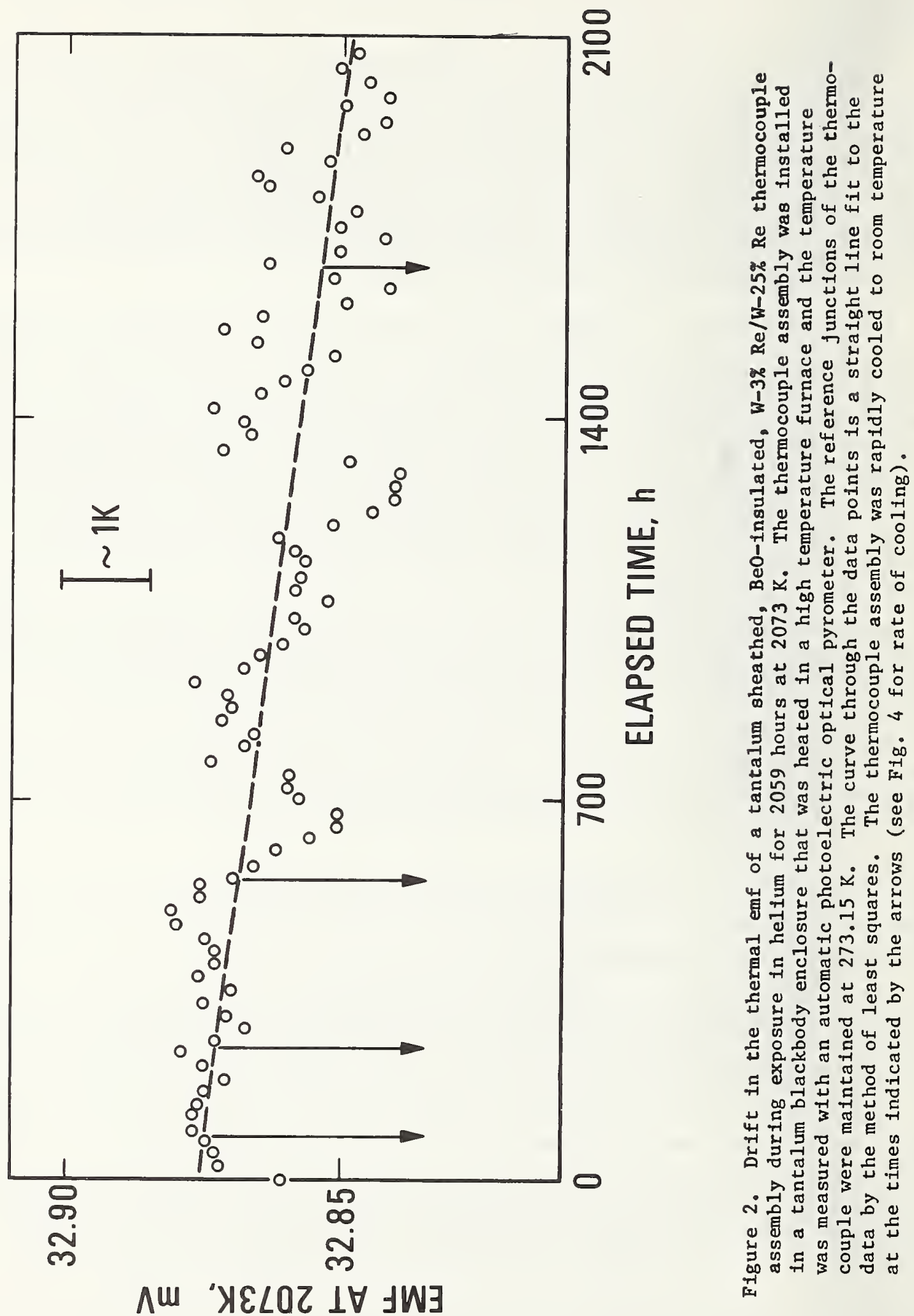


evident, the maximum deviation of any data point from the line is equivalent to only $1.2 \mathrm{~K}$. The standard deviation of residuals is equivalent to $0.5 \mathrm{~K}$ and the standard deviation of the slope is equivalent to $0.09 \mathrm{~K}$ per 1000 hours. The use of higher order terms to achieve a more precise fit of the experimental data seemed unwarranted. The oscillatory nature of the experimental data is thought to have resulted principally from some instability in the automatic photoelectric optical pyrometer.

Such oscillations were also apparent in the data obtained for the other three thermocouple assemblies. Similar treatment of the experimental data for the other thermocouple assemblies gave values for the drift at $2073 \mathrm{~K}$ of $-0.5,-0.7$, and $-0.8 \mathrm{~K}$ per 1000 hours. Measurements with the visual optical pyrometer yielded values for the drift that agreed within $0.2 \mathrm{~K}$ per 1000 hours with those derived from the automatic photoelectric pyrometer measurements. Typical results, based upon measurements with the visual optical pyrometer, are shown in Fig. 3. The data of both observers are plotted against exposure time at $2073 \mathrm{~K}$ for the same thermocouple assembly as the one used in Fig. 2. The straight line fitted to the data has a slope of $-0.010 \mu \mathrm{V} / \mathrm{h}$, which is equivalent to $-0.6 \mathrm{~K}$ per 1000 hours. The standard deviation of residuals is equivalent to $0.7 \mathrm{~K}$ and the standard deviation of the slope is equivalent to $0.15 \mathrm{~K}$ per 1000 hours. The test results for all four thermocouple assemblies are summarized in Table I.

As indicated in Figs. 2 and 3 the thermocouple assemblies were cooled to room temperature $(\sim 295 \mathrm{~K})$ on four occasions during the test; after about 88, 252, 553, and $1680 \mathrm{~h}$ of exposure. The rate of cooling on all four occasions was approximately the same and is shown in Fig. 4. The average rate of cooling during the first 2 minutes was about $400 \mathrm{~K} / \mathrm{min}$. After cooling, the thermocouple assemblies were heated to $2073 \mathrm{~K}$ over a period 1 to 4 hours in order to resume the test. It is evident from the results presented in Figs. 2 and 3 that the thermal cycling had no appreciable effect upon the thermal emf of the thermocouple at $2073 \mathrm{~K}$. During the thermal cycles which occurred after 252 and $553 \mathrm{~h}$ of exposure, the thermocouple assemblies were calibrated by intercomparison with the visual optical pyrometer at about 1195, 1395, 1590, 1795, and $2073 \mathrm{~K}$. The calibrations were performed during the heating portion of the cycle and two observers made readings with the pyrometer. A similar calibration was also performed both before and after the test. The differences between the calibrations that were performed after 252, 553 and 2059 hours of exposure and the calibration performed before the test are shown in Fig. 5 for two of the thermocouple assemblies. They are the assemblies which had the largest and the smallest measured drifts at $2073 \mathrm{~K}$ (see Table I, thermocouple Nos. 2 and 3, respectively). These data indicate the drift was also less than the equivalent of $1 \mathrm{~K}$ per 1000 hours for calibration temperatures below $2073 \mathrm{~K}$. While a small deviation between the initial calibration and the subsequent calibrations is apparent at the lower temperatures, the calibrations after 252, 553 and 2059 hours of exposure agree within estimated observer precision.

Before any significance can be attached to the small drifts that were derived from the experimental data, the measurement uncertainties must be considered. Drift in the calibrations of the optical pyrometers and changes in the spectral transmittance of the furnace window during the test are the principal factors contributing to the measurement uncertainties. The calibrations of both pyrometers were checked at about $2060 \mathrm{~K}$ before, near the middle, and after the 2059 hour drift test by the Optical Radiation Section at the NBS. The pyrometers were intercompared with the NBS standard photoelectric pyrometer (ref. 9) using a vertical resistive-heated graphite blackbody as a transfer source. A small change, equivalent to about $1.8 \mathrm{~K}$, was detected in the calibration of the automatic photoelectric pyrometer and a small correction was applied to the experimental data to account for it. It is estimated that this reduced the uncertainty in the measurements, due to any drift in the calibration of the automatic photoelectric pyrometer, to less than the equivalent of $1 \mathrm{~K}$. There was no significant change ( $\leqslant$ equivalent of $1.5 \mathrm{~K}$ ) detected in calibration of the visual optical pyrometer. The spectral transmittance of the furnace window was also checked before and after the test and no significant change was apparent in it ( $\leqslant$ equivalent of $0.5 \mathrm{~K}$ ). The calibration of the DVM was checked periodically during the test by the method described in the section on experimental procedures and apparatus. These checks indicated that uncertainties in the measurements arising from any drift in its calibration were less than the equivalent of $0.2 \mathrm{~K}$. Systematic errors introduced by other means, such as a gradual change in blackbody conditions, are thought to be small ( $\leqslant$ equivalent of $0.2 \mathrm{~K}$ ). 


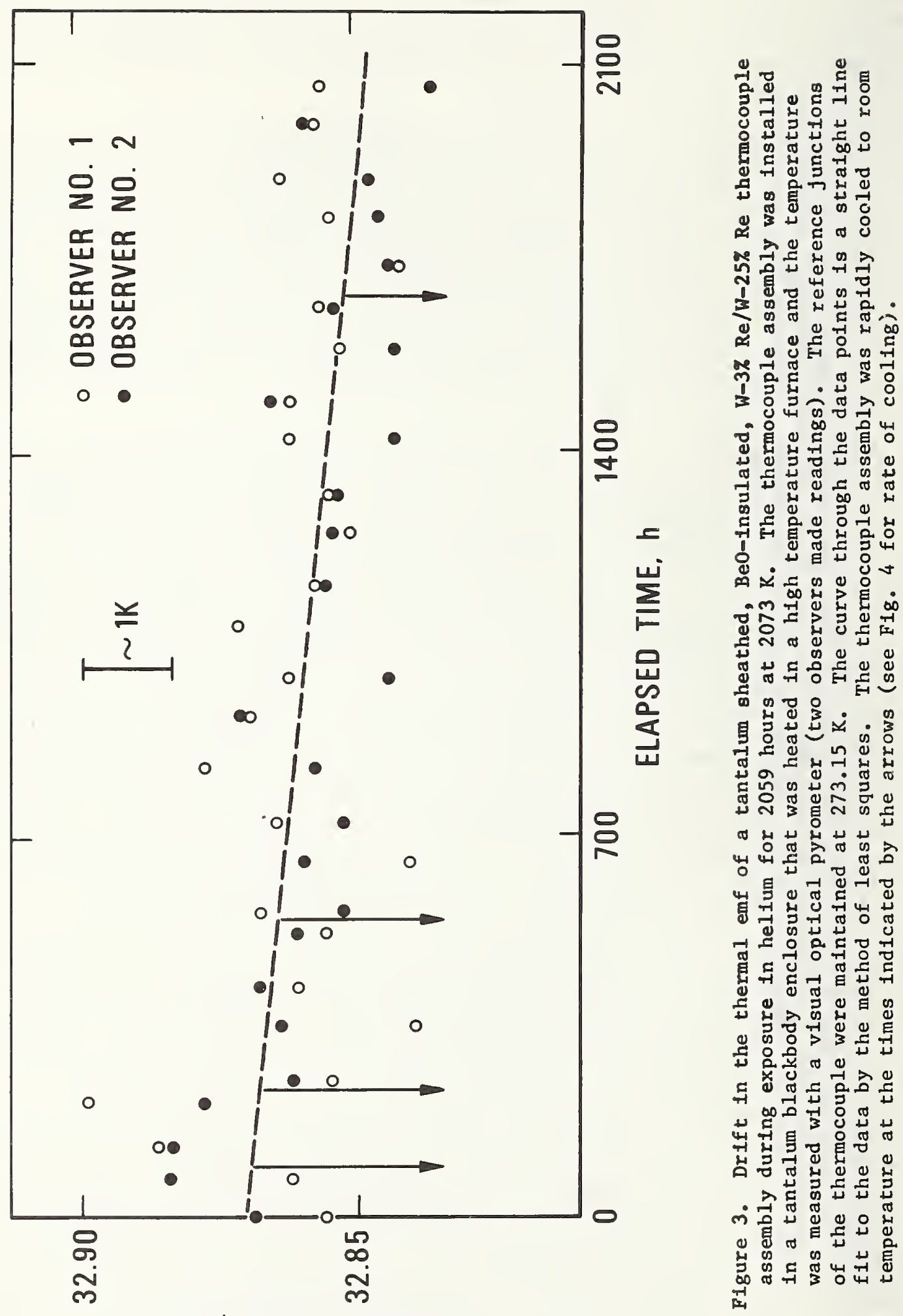




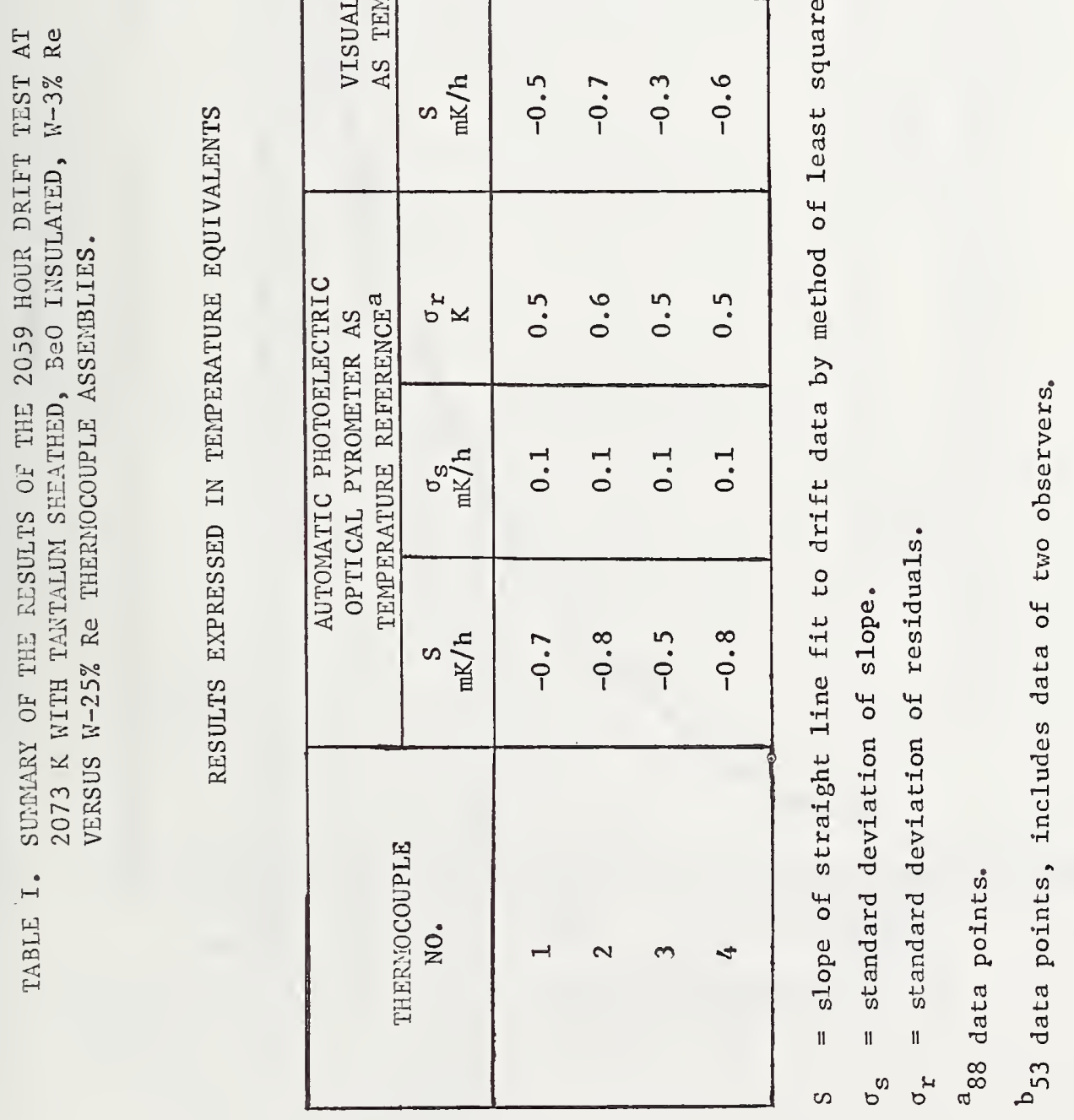




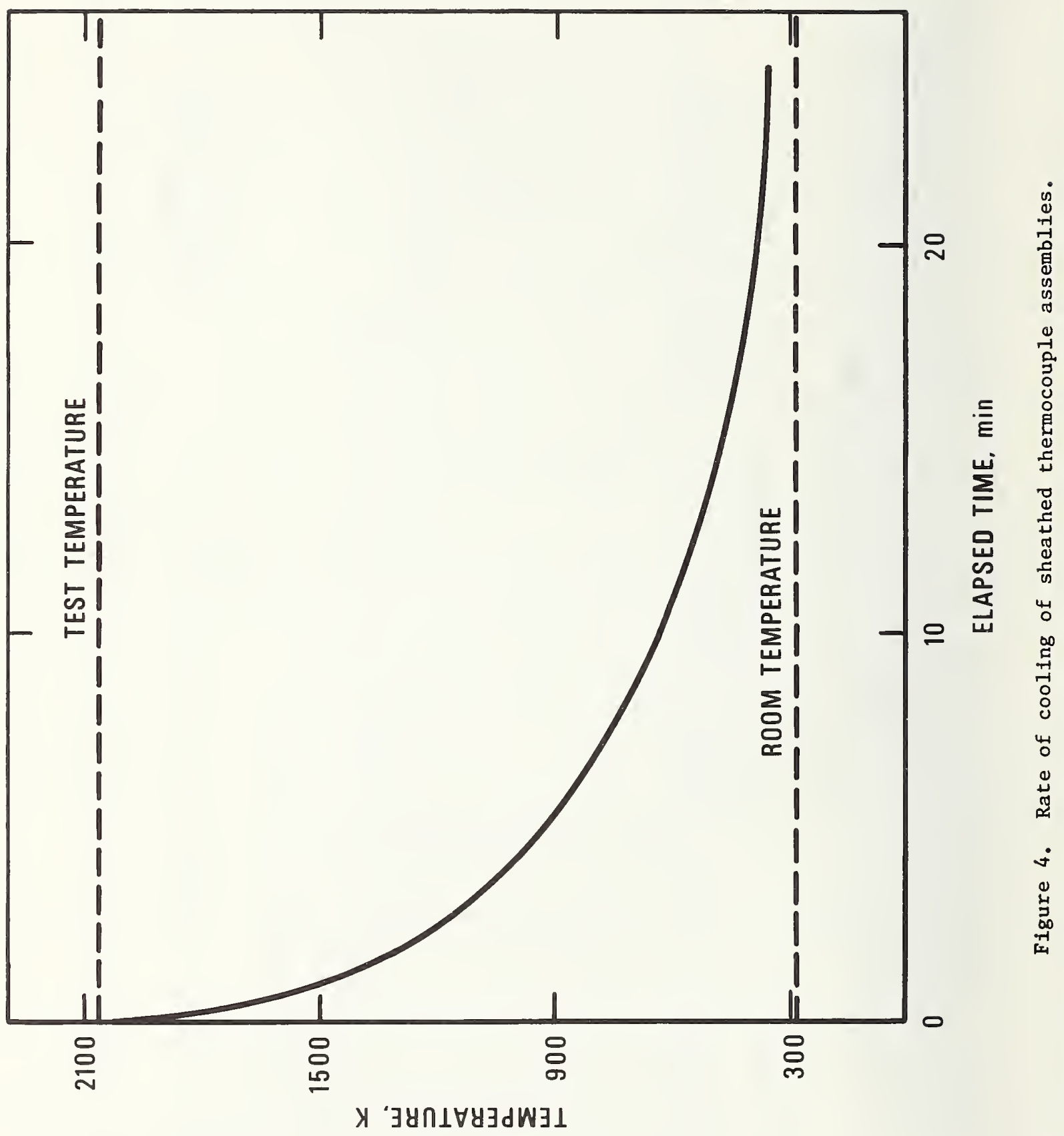




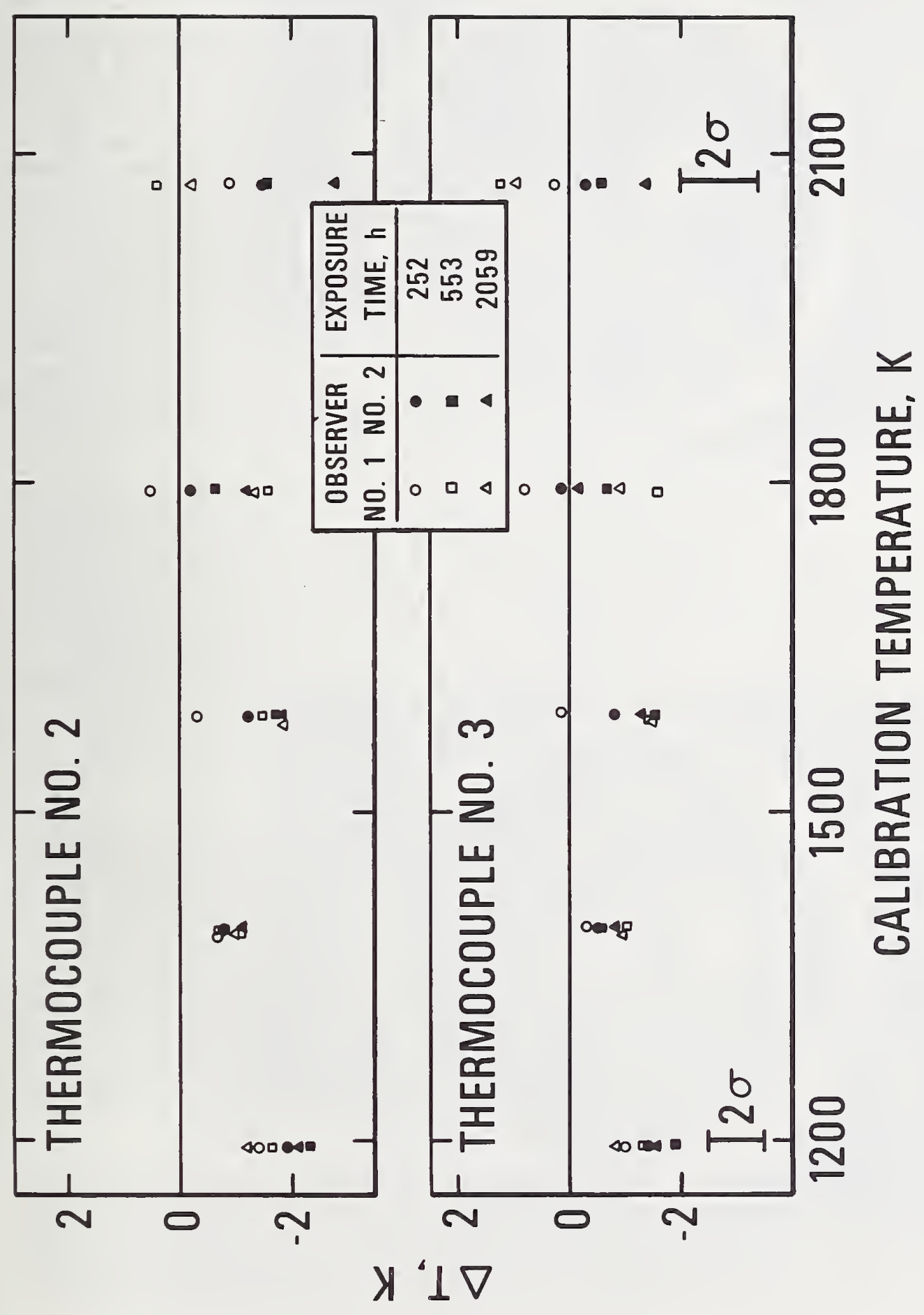

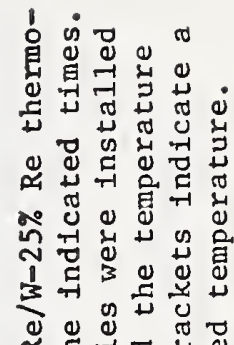

ه

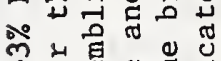

กิ मे

उ 4 点

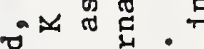

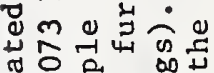

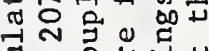

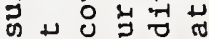

द 0 舟

宁园嵒造

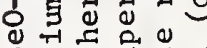

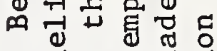

จ

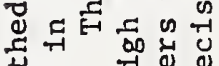

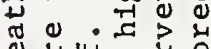

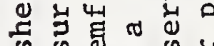

क :

青安专

겅ㅁㅁㅇㅇㅇ

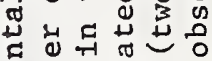

出山过

山4

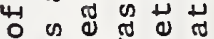

언 3 हू

듬

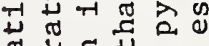

近必

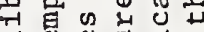

대요

उ 0 क

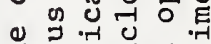

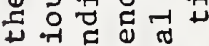

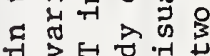

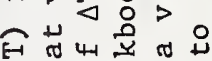

留西出

里

व $\Rightarrow 50$

类

更 $>\sum_{-1}$

ए i क त्रे मे

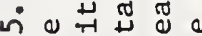
น

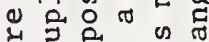

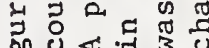
$\rightarrow$ 
If the above allowances for systematic error are added, one gets $1.9 \mathrm{~K}$ for measurements with the automatic photoelectric pyrometer and $2.4 \mathrm{~K}$ for measurements with the visual optical pyrometer. When the imprecision of the experimental data is considered together with possible systematic errors, the observed changes, which were less than $2 \mathrm{~K}$ during the 2059 hour test, are small by comparison and are therefore concluded to be insignificant.

It is interesting to compare the results of this test with those reported recently by Heckleman and Kozar (ref. 10) for an out-of-pile evaluation of some sheathed $W-3 \%$ Re versus W-25\% Re thermocouples. heckleman and Kozar measured the thermal emf drift of six tantalum sheathed, BeO insulated, $0.157 \mathrm{~cm}$ diameter, grounded junction $\mathrm{W}-3 \%$ Re versus $\mathrm{W}-25 \% \mathrm{Re}$ thermocouples during exposure to temperatures in the 1900 to $2100 \mathrm{~K}$ range for in excess of 8000 hours. The thermocouples were built commercially to rigorous specifications and supposedly represented the current state of the art as far as fabrication techniques were concerned. During the test they were inserted in a tantalum blackbody, which was heated in a high purity helium gas environment. A negative drift of 55 to $60 \mathrm{~K}$ at $2073 \mathrm{~K}$ occurred during the first 2000 hours of testing but little change occurred thereafter. Post-test examinations of the thermocouples directed towards identifying the mechanisms responsible for the drift were planned, but could not be reported, because of termination of the reactor program. Heckleman and Kozar conjectured that the drift was probably caused by chemical composition changes resulting from contamination by impurities that were present in the insulator, sheath, or on the wires. They concluded that after about 2000 hours the impurities had apparently been gettered or had diffused to some other location where they were no longer effective in promoting further drift.

The thermocouples tested by Heckleman and Kozar used crushable insulators that were compacted by swaging and had grounded junctions, while those tested in the present work had hard, sintered double-bore insulators and ungrounded junctions. This might possibly account for some difference in behavior. We attribute the highly stable behavior of the thermocouple assemblies that were fabricated at NBS primarily to the careful selection, preparation and assembly of the component materials. While the type of construction may also be a factor, its importance is thought to be secondary. In any event, from the results of these two experiments it is clear that highly reliable tantalum-sheathed W-Re type thermocouple sensors can be fabricated. Satisfactory performance for periods in excess of 8000 hours at temperatures to $2100 \mathrm{~K}$ without any appreciable emf drift is possible with suitably fabricated sensors in environments that are not intrinsically deleterious to the sensor materials.

Post-test examination of materials. At the conclusion of the $2059 \mathrm{~h}$ test, the thermocouple assemblies and tantalum blackbody were removed from the furnace as a unit and inspected. Some warpage of the tantalum sheaths was evident and each of the sheaths was fused to the tantalum blackbody at the point where it entered the $3.2 \mathrm{~cm}$ diam. enclosure (see Fig. 1). The sheath on thermocouple No. 2 was also fused to one of the tantalum radiation shields at the top of the furnace hot-zone and it had a small crack at this point. It was not clear whether the crack occurred during the test (probably on thermal cycling) or whether it occurred when the assemblies were removed from the furnace. In any event, the performance of thermocouple No. 2 was not significantly different from that of the other three thermocouples. To check on gas tightness, the sheaths on the other three thermocouple assemblies were evacuated and helium leak tested. ivo leaks were detected in any of the sheaths. Visual inspection revealed no evidence of any serious chemical attack of the tantalum sheaths or the tantalum blackbody enclosure.

The thermocouple assemblies were then removed from the blackbody enclosure and dismantled. By making transverse cuts at several places along the thermocouple assemblies the BeO insulators were easily removed from the tantalum sheaths. The thermocouple wires were free within the bores of the insulators and were also easily removed for examination. No gross chemical attack of the thermoelements, BeO insulators, or the tantalum sheaths was apparent.

Photomicrographs of transverse cross-sections that were taken at about $2 \mathrm{~cm}$ and at about $28 \mathrm{~cm}$ from the sheath tip of one thermocouple assembly are shown in Fig. 6 . The microstructures of the materials, as illustrated in the cross-section at $2 \mathrm{~cm}$, are typical of that exhibited by materials which were taken from locations up to $15 \mathrm{~cm}$ from the sheath 


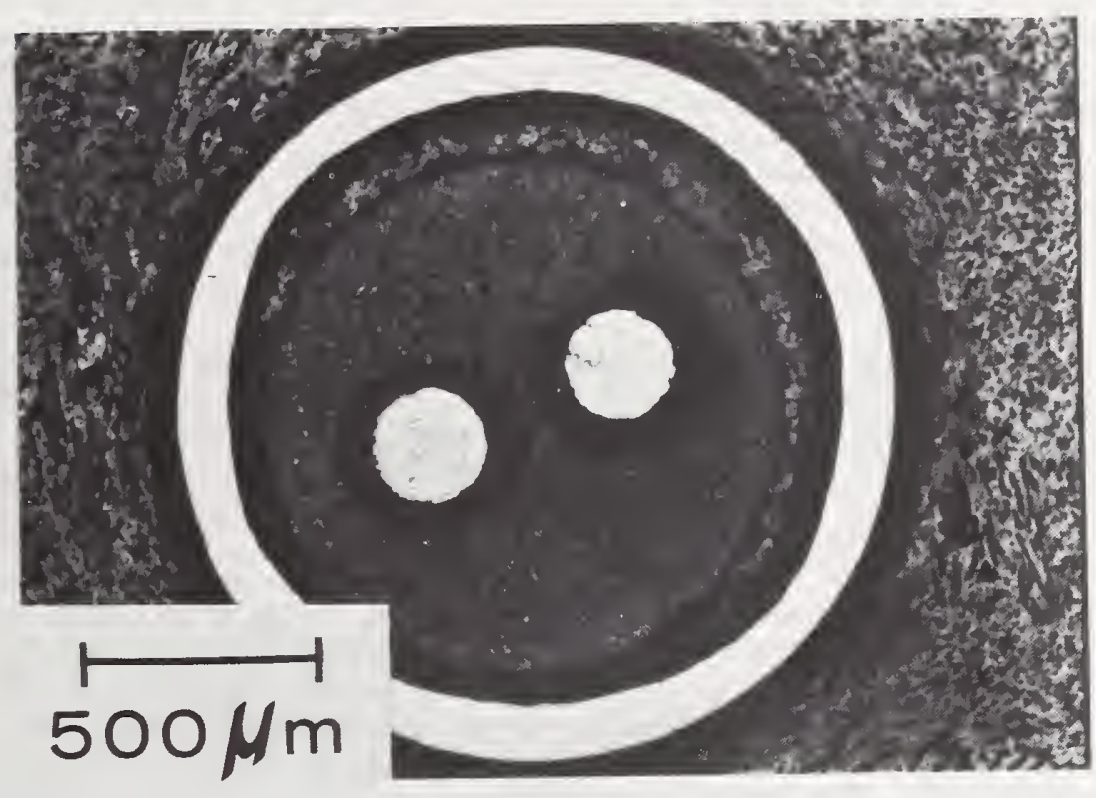

(a)

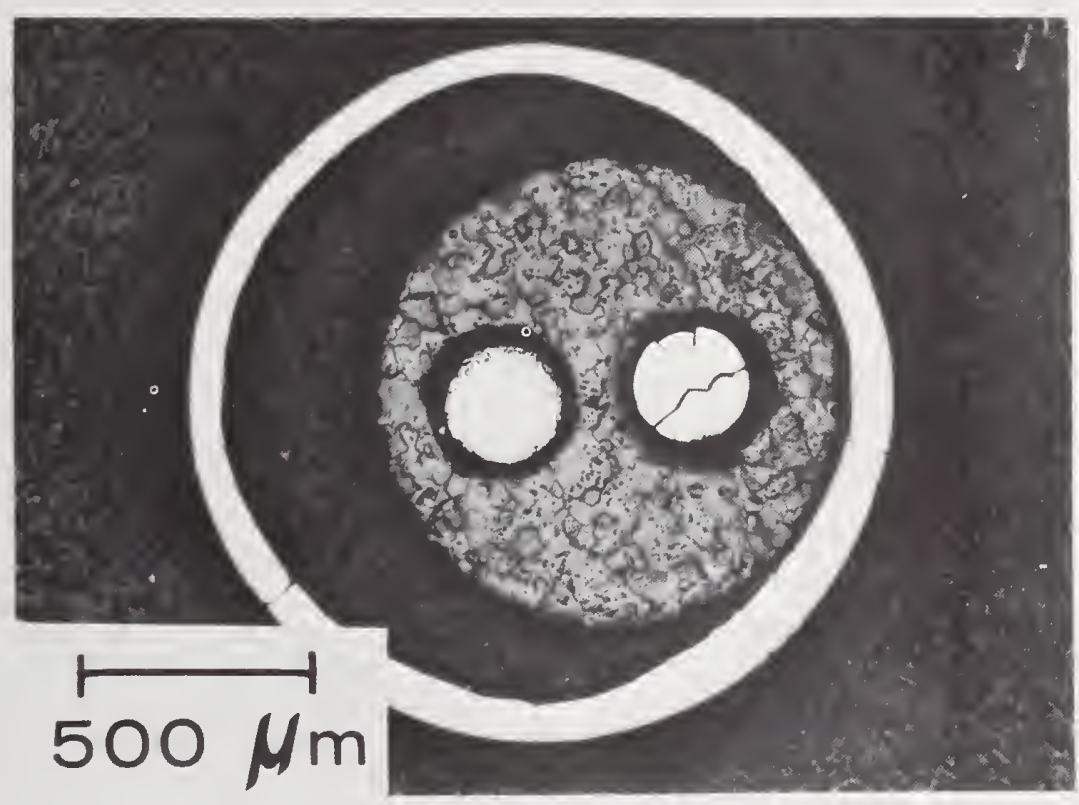

(b)

Figure ó. Photomicrographs showing transverse cross-sections of a $1.6 \mathrm{~mm}$ diameter tantalum sheathed, BeO-insulated, $W-3 \% \operatorname{Re} / W-25 \% \operatorname{Re}$ thermocouple (a) at $28 \mathrm{~cm}$ from the sheath tip where no high temperature exposure occurred, and (b) at $2 \mathrm{~cm}$ from the sheath tip where exposure for 2059 hours at $2073 \mathrm{~K}$ occurred. 
tip. The cross-section at $28 \mathrm{~cm}$ from sheath tip was taken at a location along the thermocouple assembly that was not heated. Therefore, the microstructures are typical of the materials prior to testing (and subsequent to the preparatory heat treatments and assembly). Those portions of the $\mathrm{W}-25 \%$ Re thermoelements that were in the hot-zone region of the furnace experienced substantial grain growth, with the wires exhibiting equiaxed grains roughly $50 \mu \mathrm{m}$ up to one-half wire diameter in size. In contrast, the exposed portions of the $\mathrm{W}-3 \%$ Re thermoelements experienced virtually no grain-growth. They had a fine-grained structure similar to that of the aged "starting" material. These results are to be expected from material behavior observed in earlier work (refs. 1 and 4), where bare thermoelements were exposed at temperatures up to $2400 \mathrm{~K}$ for periods as long as 1000 hours.

As shown in Fig. 7, a temperature gradient of approximately 400 to $500 \mathrm{~K} / \mathrm{cm}$ existed along the thermocouple assemblies during the test in the region between 15 and $18 \mathrm{~cm}$ from the sheath tips. Examination of the thermoelements in this region revealed that some chemical interactions had occurred at the wire surfaces. The appearance of the surfaces of both thermoelements is shown by the photomicrographs in Fig. 8. For purposes of comparison, photomicrographs showing the typical appearance of the surfaces of thermoelements in the high-temperature zone (extending from the sheath tip to $15 \mathrm{~cm}$ from tip) and in the unheated zone are included in Fig. 8. The interaction is more apparent in the $\mathrm{W}-25 \% \mathrm{Re}$ thermoelement. The surface of the $\mathrm{W}-25 \% \mathrm{Re}$ thermoelement is shown at higher magnification by the photomicrograph in Fig. 9. The formation of an apparent second phase at the grain boundaries can be seen. A longitudinal cross-section taken very near the surface of the $W-25 \%$ Re thermoelement is given in Fig. 10 and it clearly shows the presence of a second phase at the grain boundaries. The second phase presumably resulted from some attack of the wire surface by chemical contaminants. While some diffusion from the wire surface along the grain boundaries is evident, it is limited to a depth of about $10 \mu \mathrm{m}$. Transverse cross-sections of the thermoelements in this region revealed no evidence of other phases at the interior of the wire. A positive identification of the chemical composition of the second phase has not been made. However, spectrochemical analyses of specimens that were taken from the thermoelements in this region indicated a small increase in the $\mathrm{Mg}$ and $\mathrm{Ca}$ impurity levels. No significant increases in the impurity levels of $\mathrm{Al}, \mathrm{Be}, \mathrm{Fe}, \mathrm{Si}$, or Ta were detected.

The BeO tubing that was in the high temperature zone had a translucent appearance. As shown in Fig. 6 appreciable grain-growth and about a $10 \%$ reduction in the tubing diameter are evident. The grain size of the exposed BeO tubing ranges from about 30 to $90 \mu \mathrm{m}$. By comparison, the grain size of the "as received" Beo tubing was typically 1 to $5 \mu \mathrm{m}$ and virtually no change in the grain size occurred as a result of the preparatory heat treatments (vacuum degassing). The diameter reduction is thought to be a result of densification. In other tests (see section on Studies of BeO-Ta Sheath Compatibility and also ref. 1) where tubing from the same lot was exposed at temperatures in the 2000 to $2250 \mathrm{~K}$ range for prolonged periods in the presence of tantalum similar behavior was noted. In addition, in earlier work (refs. 1 and 3) a substantial increase in the purity of the exposed insulators was observed; sizable reductions were detected in the impurity levels of principally $\mathrm{Al}, \mathrm{C}, \mathrm{Ca}, \mathrm{Mg}$ and $\mathrm{Na}$. The residual impurities were suspected to have been gettered by the tantalum. The results of mass spectrographic analyses on exposed tantalum specimens from the present test further support this assumption. Typical chemical analyses are given in Table II for a specimen of the chemically cleaned, etched, and vacuum degassed tantalum tubing and for a specimen of tantalum tubing that was taken from one of the thermocouple assemblies at a point between 2 and $6 \mathrm{~cm}$ from the sheath tip.

$\mathrm{Al}, \mathrm{Ca}, \mathrm{Fe}, \mathrm{Mg}$, $\mathrm{Na}$, $\mathrm{Si}$ and $\mathrm{Ti}$, which are residual impurities in the BeO tubing, are detectable in the exposed thermocouple sheath at a level at least ten-fold greater than in the unexposed tantalum tubing. The most notable increase is that for Al. This is not surprising since $\mathrm{Al}$ is the principal impurity in the BeO tubing, where it is detectable at the 200 to $300 \mathrm{ppm}$ level (refs. 1 and 3). The BeO tubing is also the most probable source of the contaminants which were responsible for the attack noted at the surface of the thermoelements in the temperature gradient zone. 


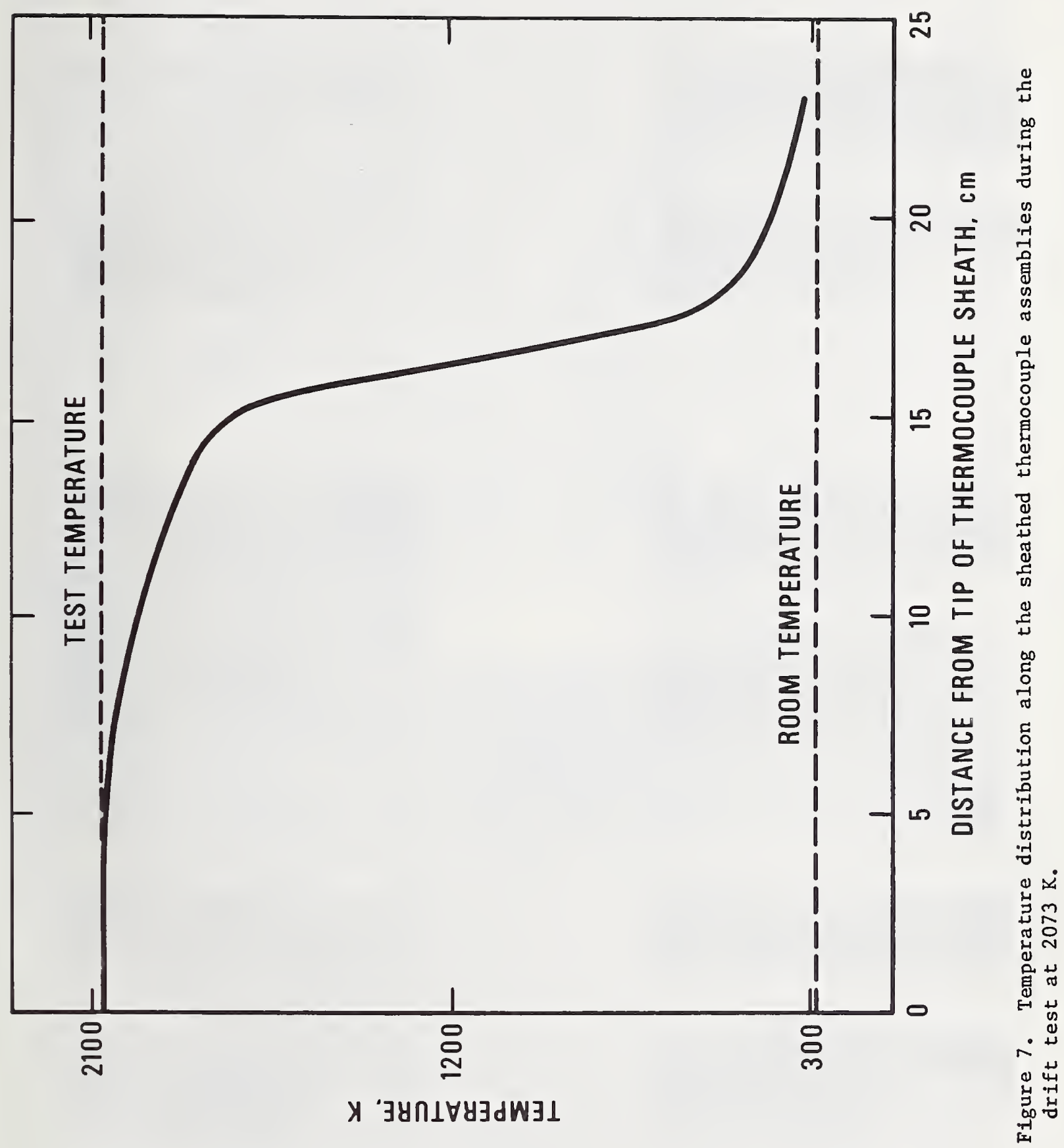



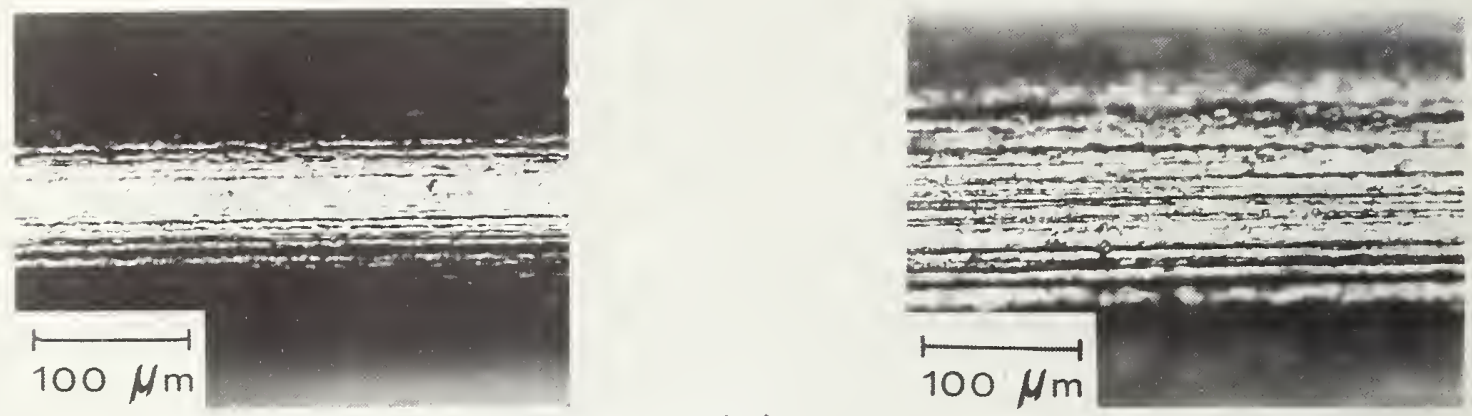

(a)
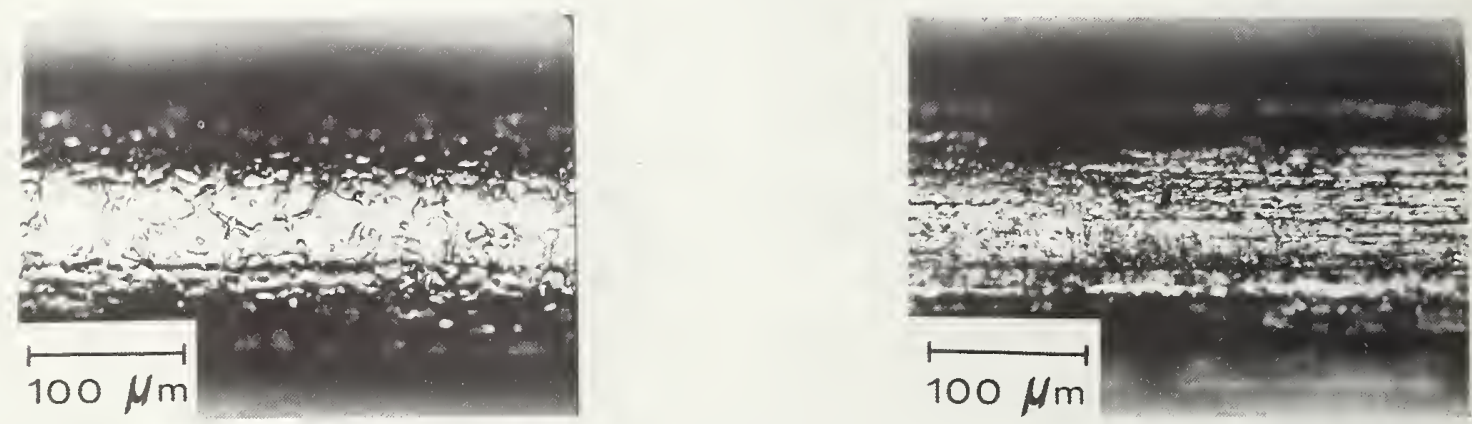

(b)
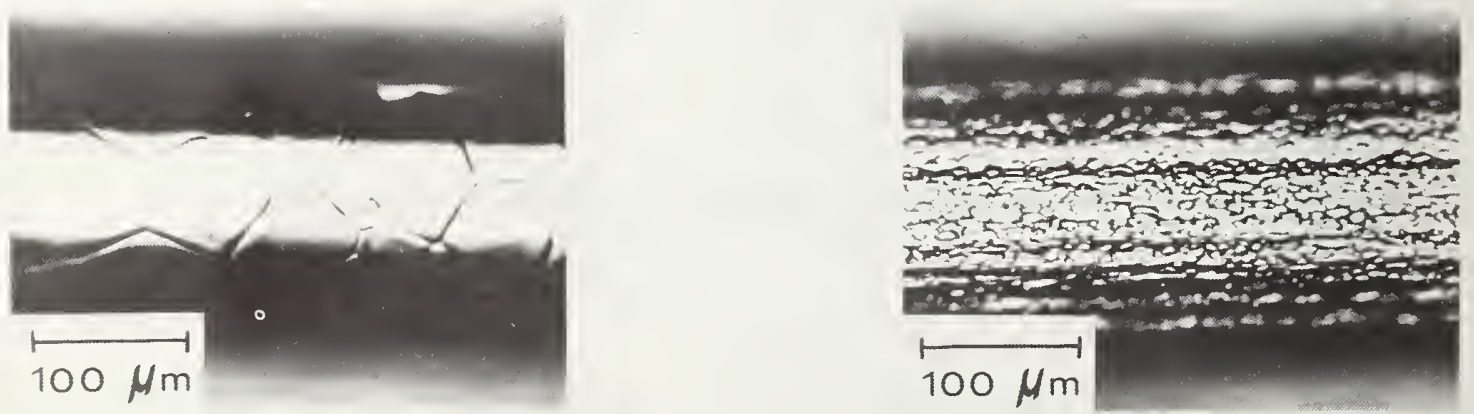

(c)

Figure 8. Photomicrographs showing the typical appearances of the surfaces of the thermoelements in various regions along the tantalum sheathed, BeO-insulated, $\mathrm{W}-3 \% \operatorname{Re} / \mathrm{W}-25 \% \operatorname{Re}$ thermocouple assemblies that were exposed for 2059 hours at $2073 \mathrm{~K}$ : (a) in the unheatedzone greater than $25 \mathrm{~cm}$ from the steath tip; (b) in the temperature-gradient zone between 15 and $18 \mathrm{~cm}$ from the sheath tip; and (c) in the high temperature zone extending from the sheath tip to $15 \mathrm{~cm}$ from the tip. 


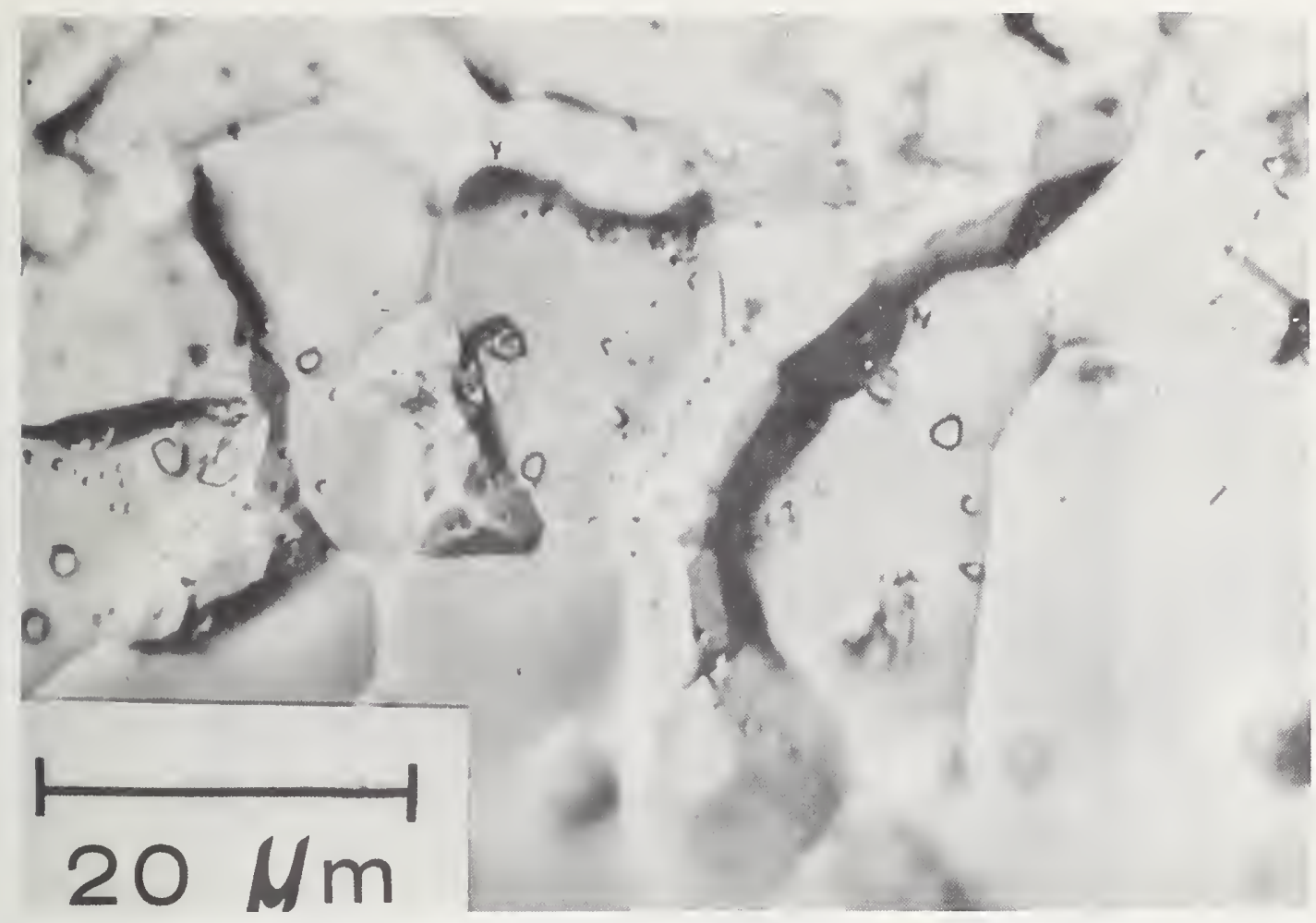

Figure 9. Photomicrograph showing the surface of the W-25\% Re thermoelement in Fig. 8(b) at higher magnification.
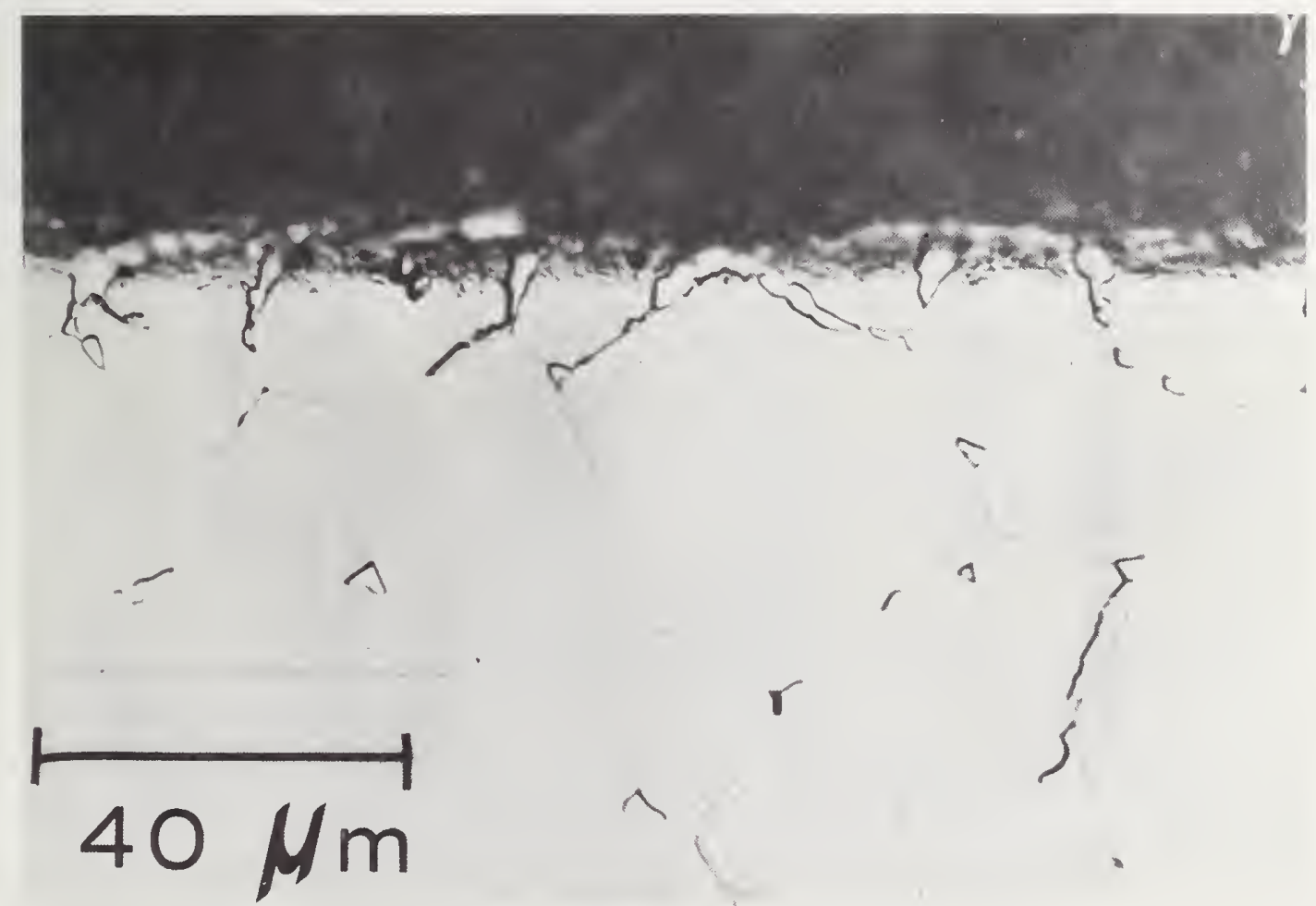

Figure 10. Photomicrograph exhibiting a longitudinal cross-section just below the surface of the W-25\% Re thermoelement, whose surface is shown in Figs. $8(\mathrm{~b})$ and 9. 
TABLE II. MASS SPECTROGRAPHIC ANALYSES OF TANTALUM THERMOCOUPLE SHEATHS (composition in $\mathrm{Ppm}$ by weight)

\begin{tabular}{|c|c|c|}
\hline Element & $\begin{array}{l}\text { Chemically cleaned, } \\
\text { etched, and vacuum } \\
\text { degassed specimen }\end{array}$ & $\begin{array}{l}\text { Specimen }^{\text {b from }} \\
\text { sheathed thermocouple } \\
\text { assembly after } 2059 \mathrm{~h} \\
\text { at } 2073 \mathrm{~K}\end{array}$ \\
\hline $\mathrm{Li}$ & 0.001 & 0.002 \\
\hline $\mathrm{Be}$ & 0.005 & 0.2 \\
\hline B & 0.01 & 0.03 \\
\hline F & 2. & 30. \\
\hline $\mathrm{Na}$ & 0.4 & 6. \\
\hline $\mathrm{Mg}$ & 0.1 & 5. \\
\hline $\mathrm{A} 1$ & 0.1 & 150. \\
\hline Si & 0.2 & 6. \\
\hline $\mathbf{P}$ & 0.05 & 3. \\
\hline$S$ & 0.3 & 10. \\
\hline $\mathrm{C} 1$ & 0.4 & 2. \\
\hline $\mathrm{K}$ & 2. & 5. \\
\hline $\mathrm{Ca}$ & 0.2 & 2. \\
\hline Sc & $<0.03$ & 0.03 \\
\hline Ti & 0.03 & 7. \\
\hline $\mathrm{V}$ & 0.05 & 1. \\
\hline $\mathrm{Cr}$ & 0.1 & 0.5 \\
\hline Mn & 0.03 & 0.2 \\
\hline $\mathrm{Fe}$ & 0.7 & 7. \\
\hline Co & $<0.02$ & 0.2 \\
\hline $\mathrm{Ni}$ & $<0.1$ & 0.3 \\
\hline $\mathrm{Cu}$ & 3. & 2. \\
\hline $\mathrm{Zn}$ & 3. & 5. \\
\hline $\mathrm{Ga}$ & $<0.01$ & $<0.01$ \\
\hline $\mathrm{Ge}$ & $\leq 0.02$ & $\leq 0.04$ \\
\hline As & $<0.04$ & $<0.04$ \\
\hline $\mathrm{Se}$ & $<3$ & $<3$ \\
\hline $\mathrm{Br}$ & $<0.1$ & 0.1 \\
\hline $\mathrm{Rb}$ & $<0.005$ & 0.03 \\
\hline $\mathrm{Sr}$ & $<0.005$ & 0.05 \\
\hline Y & $\leq 1$ & $\leq 0.2$ \\
\hline $\mathrm{Zr}$ & $<0.3$ & 0.5 \\
\hline $\mathrm{Nb}$ & 50. & 50. \\
\hline Mo & 0.1 & 0.2 \\
\hline Ru & $<0.06$ & $<0.06$ \\
\hline $\mathrm{Rh}$ & $<0.02$ & $<0.02$ \\
\hline $\mathrm{Pd}$ & $<0.2$ & $<0.2$ \\
\hline $\mathrm{Ag}$ & $\leq 0.04$ & 0.4 \\
\hline $\mathrm{Cd}$ & $<0.04$ & 0.4 \\
\hline In & $<0.06$ & $<0.06$ \\
\hline
\end{tabular}


TABLE II, continued

(composition in $\mathrm{ppm}$ by weight)

\begin{tabular}{|c|c|c|}
\hline Element & $\begin{array}{l}\text { Chemically cleaned, } \\
\text { etched, and vacuum } \\
\text { degassed specimen }\end{array}$ & $\begin{array}{l}\text { Specimen }^{\mathrm{b}} \text { from } \\
\text { sheathed thermocouple } \\
\text { assemb1y after } 2059 \mathrm{~h} \\
\text { at } 2073 \mathrm{~K}\end{array}$ \\
\hline $\mathrm{Sn}$ & $<0.03$ & 0.3 \\
\hline $\mathrm{Sb}$ & $<0.02$ & $\leq 0.03$ \\
\hline $\mathrm{Te}$ & $<0.04$ & $<0.04$ \\
\hline I & $<0.02$ & $\leq 0.02$ \\
\hline Cs & $<0.02$ & $<0.02$ \\
\hline $\mathrm{Ba}$ & $<0.01$ & 0.4 \\
\hline $\mathrm{La}$ & $<0.01$ & $<0.01$ \\
\hline $\mathrm{Ce}$ & $<0.01$ & $<0.02$ \\
\hline $\operatorname{Pr}$ & $<0.01$ & $<0.01$ \\
\hline $\mathrm{Nd}$ & $<0.03$ & $<0.03$ \\
\hline Sm & $<0.03$ & $<0.03$ \\
\hline $\mathrm{Eu}$ & $<0.02$ & $<0.02$ \\
\hline Gd & $<0.03$ & $<0.03$ \\
\hline $\mathrm{Tb}$ & $<0.01$ & $<0.01$ \\
\hline Dy & $<0.04$ & $<0.04$ \\
\hline Ho & $<0.01$ & $<0.01$ \\
\hline Er & $<0.03$ & $<0.03$ \\
\hline $\mathrm{Tm}$ & $<0.01$ & $<0.01$ \\
\hline $\mathrm{Yb}$ & $<0.03$ & $<0.03$ \\
\hline $\mathrm{Lu}$ & $<0.01$ & $<0.01$ \\
\hline $\mathrm{Hf}$ & $<0.1$ & $<0.1$ \\
\hline W & 10. & 20 \\
\hline $\operatorname{Re}$ & $<0.05$ & 0.1 \\
\hline $0 \mathrm{~s}$ & $<0.1$ & $<0.1$ \\
\hline Ir & $<0.1$ & $<0.1$ \\
\hline $\mathrm{Pt}$ & $<1$ & $<1$ \\
\hline $\mathrm{Au}$ & $<2$ & $<2$ \\
\hline $\mathrm{Hg}$ & $<0.03$ & $<0.03$ \\
\hline T1 & $<0.03$ & $<0.03$ \\
\hline $\mathrm{Pb}$ & $<0.1$ & 0.4 \\
\hline $\mathrm{Bi}$ & $<0.03$ & $<0.03$ \\
\hline Th & $<0.2$ & $<0.2$ \\
\hline U & $<0.3$ & $<0.2$ \\
\hline $\mathrm{Ta}$ & Balance & Balance \\
\hline
\end{tabular}

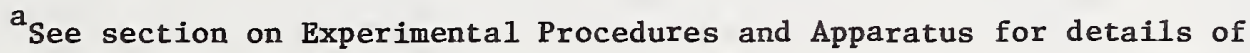
specimen preparation.

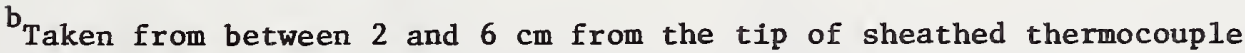
assembly. 
Drift tests with BeO-insulated $W-3 \%$ Re versus $W-25 \%$ Re thermocouples were performed in argon at $2250 \mathrm{~K}$ for 1100 hours and at $2400 \mathrm{~K}$ for 307 hours. were used in each test. The test results were as follows:

Newly constructed thermocouples

Thermal emf drift. The value of the thermal emf at $2250 \mathrm{~K}$ as a function of the time of exposure was typically that illustrated in Fig. 11. The data illustrated used the photoelectric pyrometer as a reference. For each thermocouple, the experimental data were fit by the method of least squares to either a quadratic or cubic equation. The results for all four thermocouples are summarized in Table III.

For three of the thermocouples (Nos. 2, 3 and 4) the largest change after 1100 hours was equivalent to only about $+3 \mathrm{~K}$. The other thermocouple (No. 1) exhibited a change equivalent to about $+11 \mathrm{~K}$. The changes computed for the same thermocouple from measurements with the photoelectric and the visual pyrometers differed slightly, but agreed to within the combined precision of the measurements (the standard deviation of the residuals was equivalent to about $0.4 \mathrm{~K}$ for the photoelectric pyrometer data and to about $1 \mathrm{~K}$ for the visual pyrometer data). The calibrations of both pyrometers were checked ${ }^{8}$ before and after the drift test and these checks indicated that no appreciable change occurred in the calibration of either instrument $(<1 \mathrm{~K}$ for the photoelectric pyrometer and $<1.5 \mathrm{~K}$ for the visual optical pyrometer). A check of the furnace window before and after the test indicated no significant change (equivalent to $<0.5 \mathrm{~K}$ ) occurred in its transmittance.

Considering the possibility of changes in the calibration of the pyrometers and in the transmittance of the furnace window, together with the scatter in the measurements and the nature of the drift results, it is perhaps better to describe the thermal emf of thermocouples 2, 3 and 4 as being stable during the 1100 hour test period to within the equivalent of about $\pm 2 \mathrm{~K}$ at $2250 \mathrm{~K}$.

The value of the thermal emf at $2400 \mathrm{~K}$ as a function of time was typically that illustrated in Fig. 12. Again, the data illustrated were obtained with the photoelectric pyrometer as a reference. because of a gradual sagging of the Ta blackbody enclosure (about $6 \mathrm{~mm}$ in 307 hours), the test was terminated at 307 hours rather than risk failure of the enclosure and damage to the furnace. The results for four of the thermocouples in the test are summarized in Table IV. The values of the drift were obtained from curves (either linear or quadratic) that were fit to the experimental data by the method of least squares. The drift in the four thermocouples varied from about $+3 \mathrm{~K}$ to about $+11 \mathrm{~K}$ at $2400 \mathrm{~K}$ after 307 hours of exposure. A fifth thermocouple in the test behaved erratically after approximately 100 hours of exposure, and the results are not included in the summary. Post-test examination revealed a region of gross erosion of the Beo insulators that bared the thermoelements (as described in more detail in the next section). It is likely that electrical shorting of the thermoelements occurred, thus accounting for the erratic behavior of the fifth thermocouple.

Material behavior. Exposure of the insulated thermocouples at 2250 and $2400 \mathrm{~K}$ resulted in some undesirable material degradation and interaction effects that were not observed in previous tests at $2073 \mathrm{~K}$ (refs. 1 and 3). In both the $2250 \mathrm{~K}$ and the $2400 \mathrm{~K}$ test, material loss or erosion of the $\mathrm{BeO}$ occurred in the hot zone. At $2400 \mathrm{~K}$, the erosion was substantial and bared the thermoelements; for a typical thermocouple, this occurred near the measuring junction of the thermocouple (see Fig. 13) and also in a region 4 to $7 \mathrm{~cm}$ above the measuring junction. At $2250 \mathrm{~K}$, erosion of the BeO insulator in comparable sections of the thermocouples was also evident, but the loss of the BeO was not sufficient to bare the thermoelements.

Further, those sections of BeO insulator that were located just outside of the high temperature zone of the furnace exhibited a metallic deposit on the outer surface of the $\mathrm{BeO}$ (see Fig. 14). The deposit could be observed as a thin metal film on the BeO insulator and as beads of metal varying from $5 \mu \mathrm{m}$ diameter to $400 \mu \mathrm{m}$ in length. Samples from

8

Performed by the Optical Radiation Section of the NBS . 


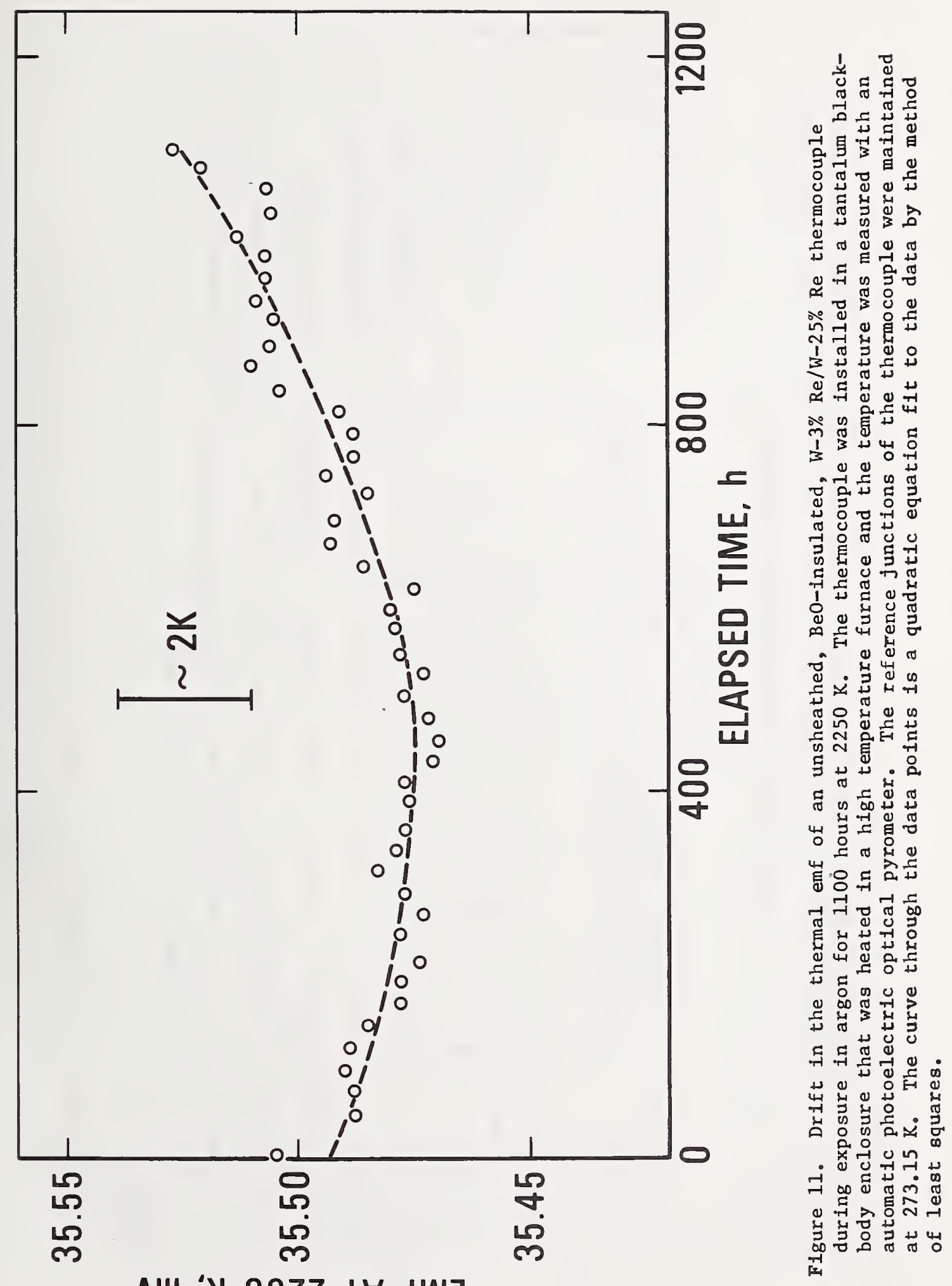

$\Lambda$ 'X $09 Z 2 \perp \forall \unlhd W \exists$ 


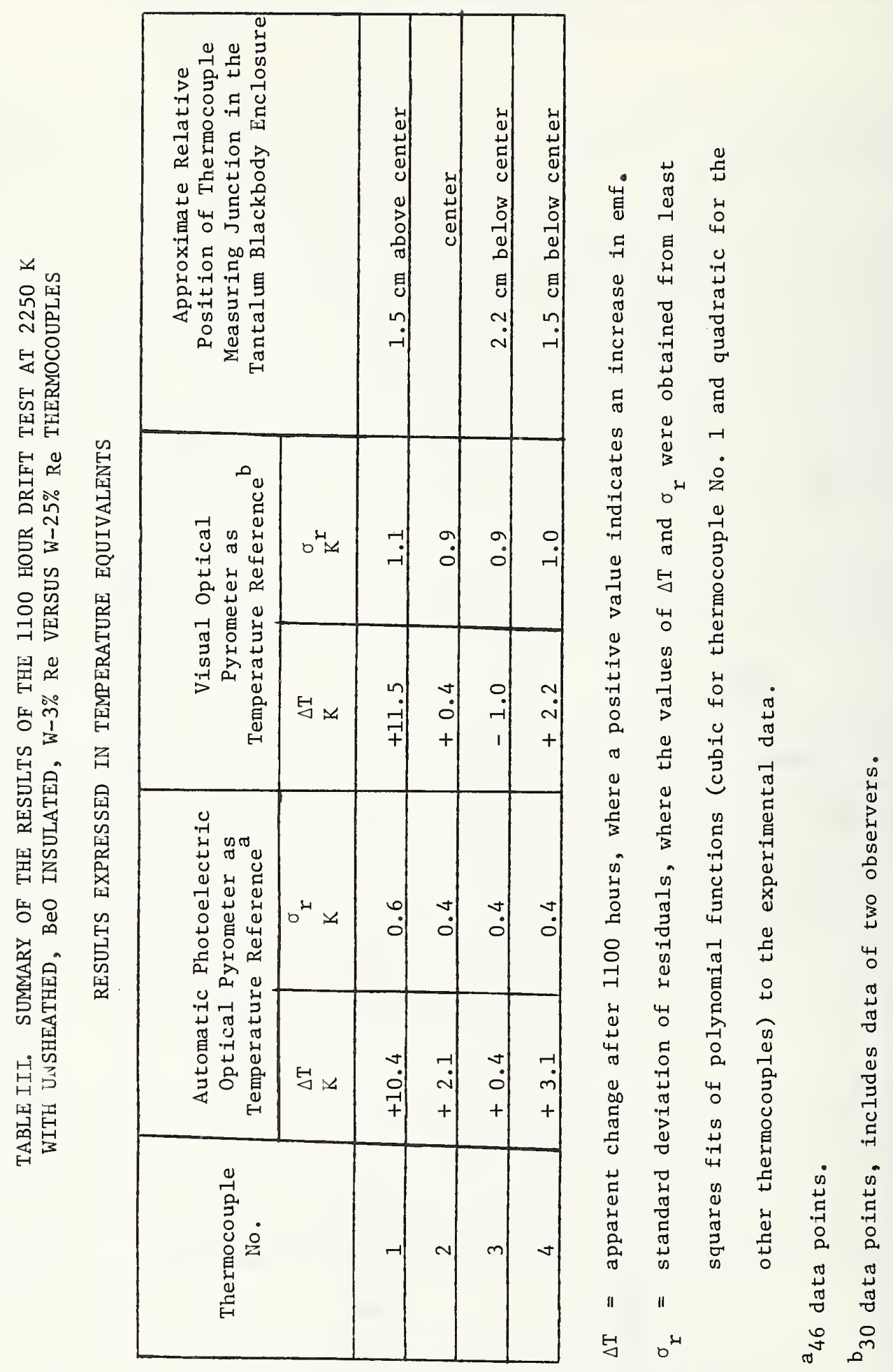




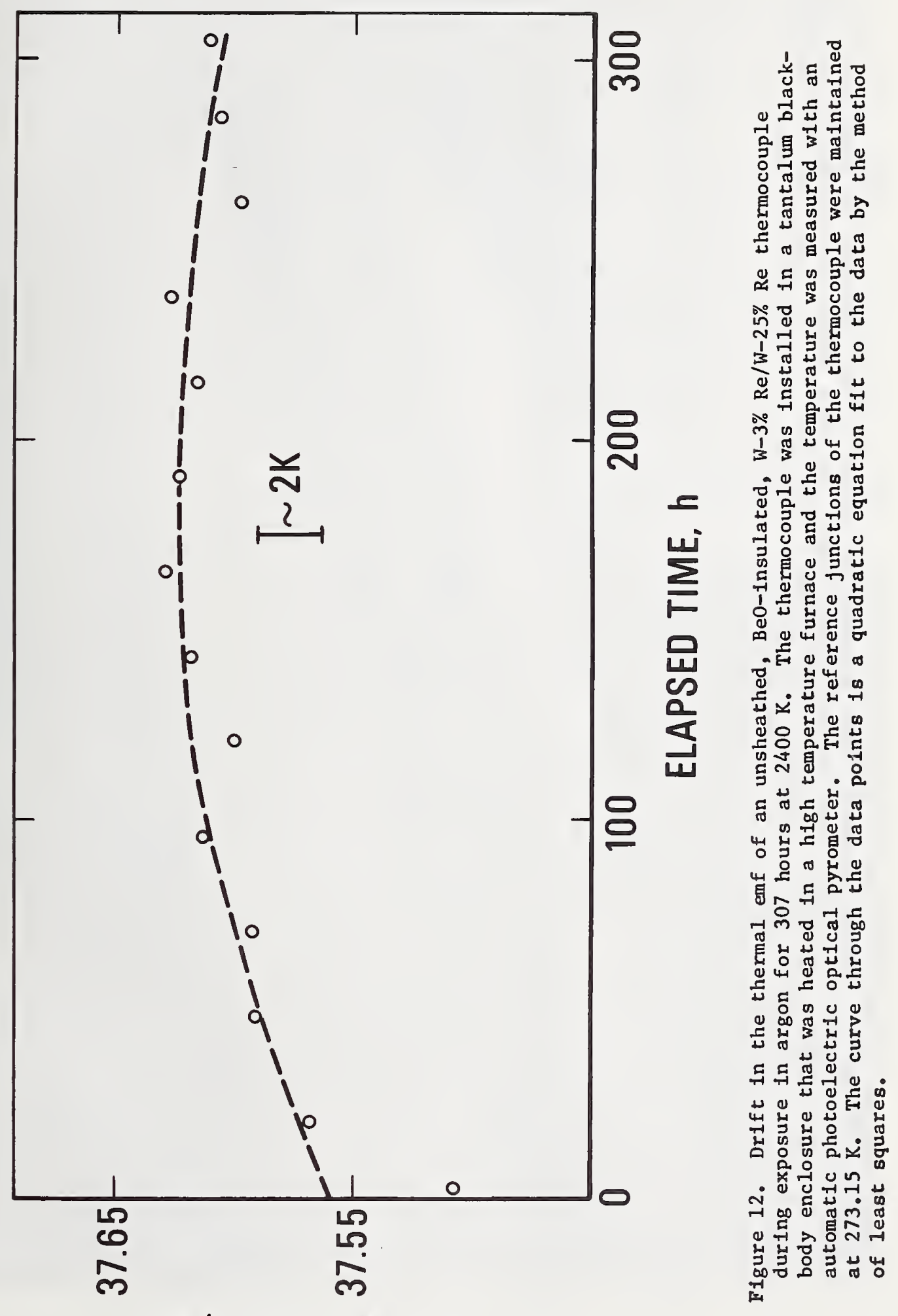

$\Lambda 山 ' \times 00 t 乙 \perp \forall \unlhd W \exists$ 


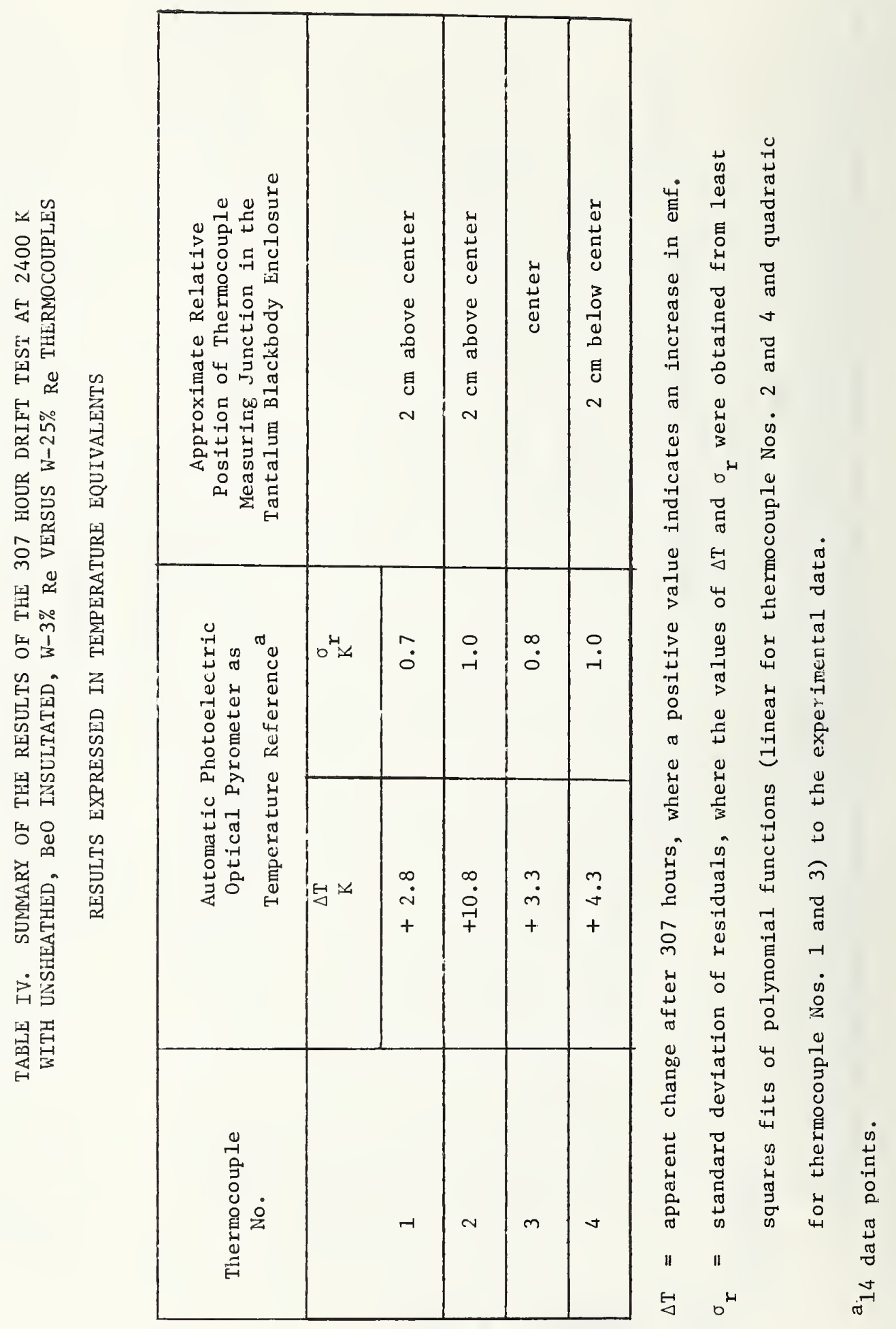




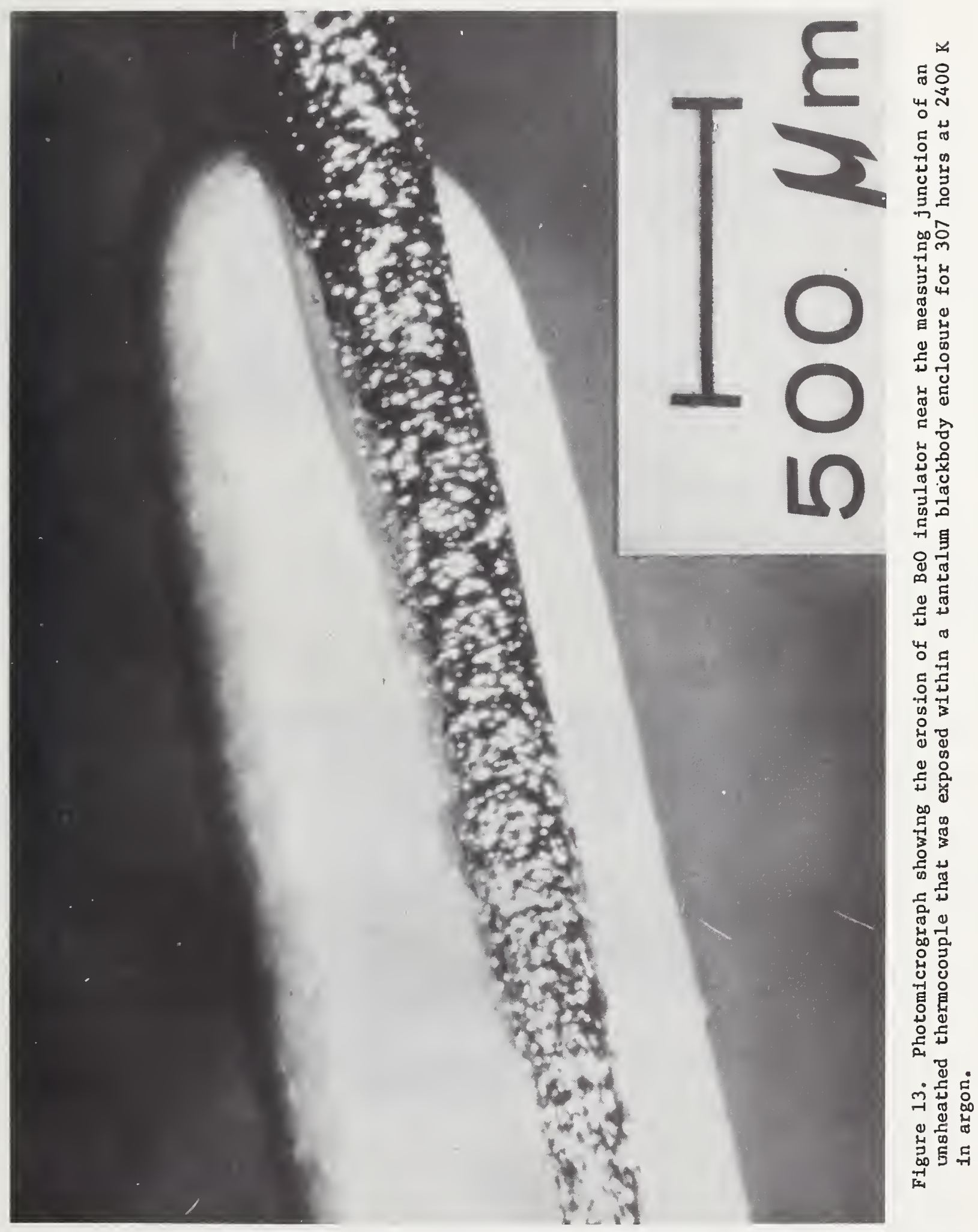




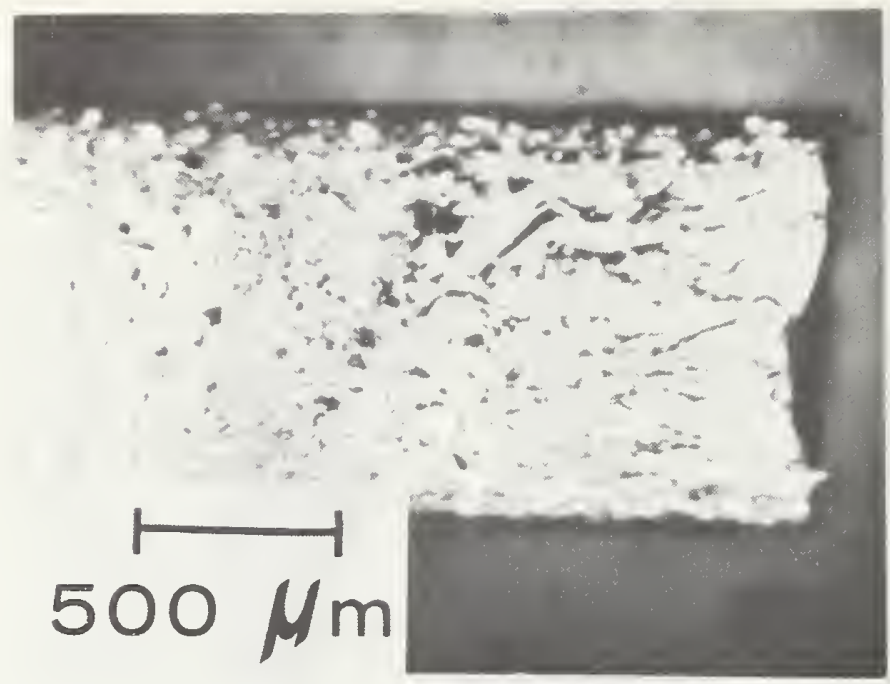

(a)

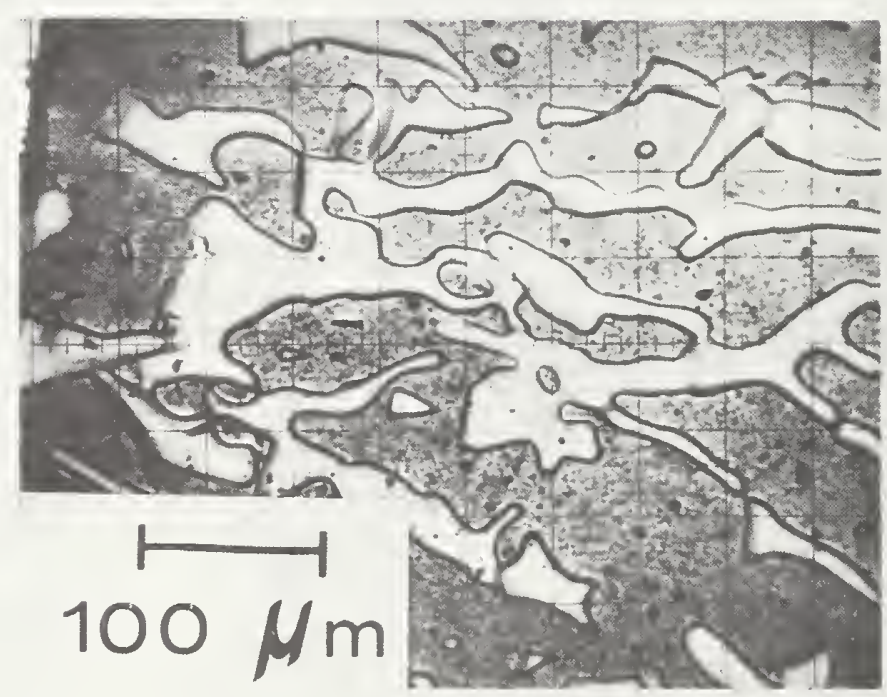

(b)

Figure 14. Deposit of beryllium on the BeO insulator in a region about $18 \mathrm{~cm}$ above the measuring junction of an unsheathed thermocouple that was exposed within a tantalum blackbody enclosure for 307 hours at $2400 \mathrm{~K}$ in argon, as seen by (a) reflected light microscope, and (b) scanning electron microscope. 
both the $2400 \mathrm{~K}$ and the $2250 \mathrm{~K}$ test were examined using electron and ion probe microanalysis. The deposit was identified as $\mathrm{Be}$. io evidence of metallic $\mathrm{Be}$ in the interior of the BeO insulator could be observed under the microscope. The bore of the BeO insulator was free of any visible deposit throughout the total length of the insulator.

In addition, in the $2250 \mathrm{~K}$ test the Be deposit that was found on thermocouple No. I happened to occur in a section where there was about a $3 \mathrm{~mm}$ gap between adjacent lengths of the BeO insulating tubing. Coarse examination did not reveal a metallic deposit on the exposed thermoelements. Nevertheless, thermocouple No. I experienced a relatively large change $(+11 \mathrm{~K})$ in its thermal emf. The possibility that the metallic deposit at the gap in the insulators resulted in electrical shunting between the thermoelements is discounted because the emf of the thermocouple increased during the test.

Besides these effects, other undesirable material effects were also observed in the $2400 \mathrm{~K}$ test. On one thermocouple, the erosion of the BeO insulators in the hot zone was sufficient to bare several centimeters of the $\mathrm{W}-3 \%$ Re thermoelement. A formation of large equiaxed grains could be observed on the thermoelement in place of the usual elongated fine-grained structure. Conventional photomicroscopy of a transverse crosssection revealed an irregular metallic coating of up to $50 \mathrm{\mu m}$ thickness on the wire (see Fig. 15). Llectron and ion probe microanalysis revealed this to be $\mathrm{Ta}$. In the region of the coating, the $\mathrm{W}-3 \%$ Re thermoelement did not retain its usual ductility.

In addition to the material loss of the BeO, those portions of the BeO that were at a temperature higher than the phase transformation temperature of approximately $2320 \mathrm{~K}$ (ref. 11) exhibited micro-cracks and were opaque. Those sections of the BeO that were below the phase transformation temperature exhibited the normal translucence, large grain size and shrinkage (densification) of approximately $10 \%$ in the diameter. Microcracking of $\mathrm{BeO}$ at temperatures above the phase transformation temperature is often observed (ref. II) and for this reason the material is probably not well suited for use above that temperature.

\section{STUDIES OF BeO-Ta SHEATH CORPATIBILITY}

Samples of BeO contained in the open-ended Ta sheaths were exposed for 50 hours, at $2073 \mathrm{~K}, 2250 \mathrm{~K}$ and $2400 \mathrm{~K}$ in argon. Tests were also performed for 307 hours at $2400 \mathrm{~K}$ and for 1100 hours at $2250 \mathrm{~K}$. The exposed Ta sheaths exhibited no gross differences in behavior from those samples of Ta sheaths, also exposed in these tests, that did not contain Beo. Typically, large grains of the order of 200 to $500 \mu \mathrm{m}$ formed in the tantalum with degassing, and little change in the microstructure occurred thereafter. In some regions, the Ta sheath exhibited pores along the inner surface of the sheath. The pores were observed also in the degassed assembly (see Fig. 16), and are thought to be the result of the sheath fabrication process, when the sheath was shrunk over a mandrel. The observations suggest that with high temperature exposure a pore breaks into several smaller pores.

After exposure of the Ta-BeO assemblies, the BeO insulators could be removed from the sheaths if the sheath was first cut with a diamond saw a few millimeters above the closed end of the tube. The BeO from the assemblies exposed for 50 hours at $2073 \mathrm{~K}$ and $2250 \mathrm{~K}$ exhibited similar behavior. The grain size was typically 15 to $60 \mathrm{\mu m}$, as compared to 1 to $5 \mu \mathrm{m}$ for the degassed $\mathrm{BeO}$. In addition, the originally opaque BeO had attained a translucent appearance, which undoubtedly occurred as a result of the increase in the grain size. A transverse cross-section of a $\mathrm{Ta}-\mathrm{BeO}$ assembly before and after exposure is shown in Fig. 17. The BeO insulators were reduced in diameter by about $10 \%$ as a result of the high temperature exposure. The reduction in diameter is essentially the same as that observed, in an earlier BeO-insulated thermocouple test (ref. 1) which exposed BeO in the presence of tantalum for 1029 hours at $2073 \mathrm{~K}$ (the BeO was contained in a tantalum blackbody enclosure for this test). In the test of the sheathed thermocouple assemblies, which is described in a previous section, similar behavior was also noted. Essentially no evidence of erosion or other material loss of $\mathrm{BeO}$ has been observed in any of the tests at $2073 \mathrm{~K}$. It is therefore concluded that the reduction in diameter is merely shrinkage resulting from further densification of the BeO. 


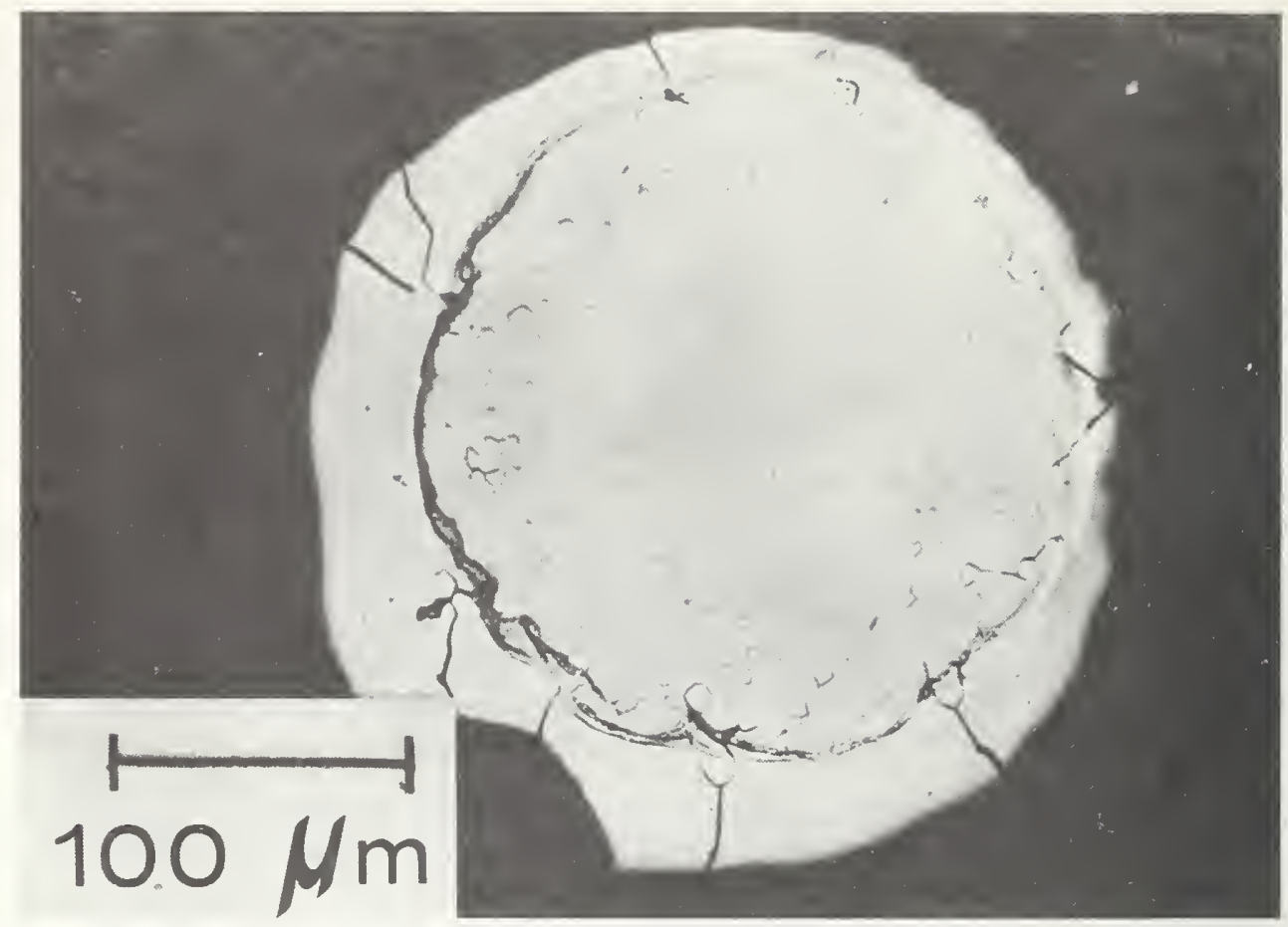

Figure 15. Photomicrograph showing a transverse cross-section of a $W-3 \%$ Re thermoelement from an unsheathed thermocouple that was exposed within a tantalum blackbody enclosure for 307 hours at $2400 \mathrm{~K}$ in argon. The cross-section was taken at about $6 \mathrm{~cm}$ above the measuring junction of the thermocouple where the BeO insulator had eroded away and bared the thermoelement. The irregular outer coating of up to $50 \mu \mathrm{m}$ thickness was identified as tantalum by electron probe microanalysis.

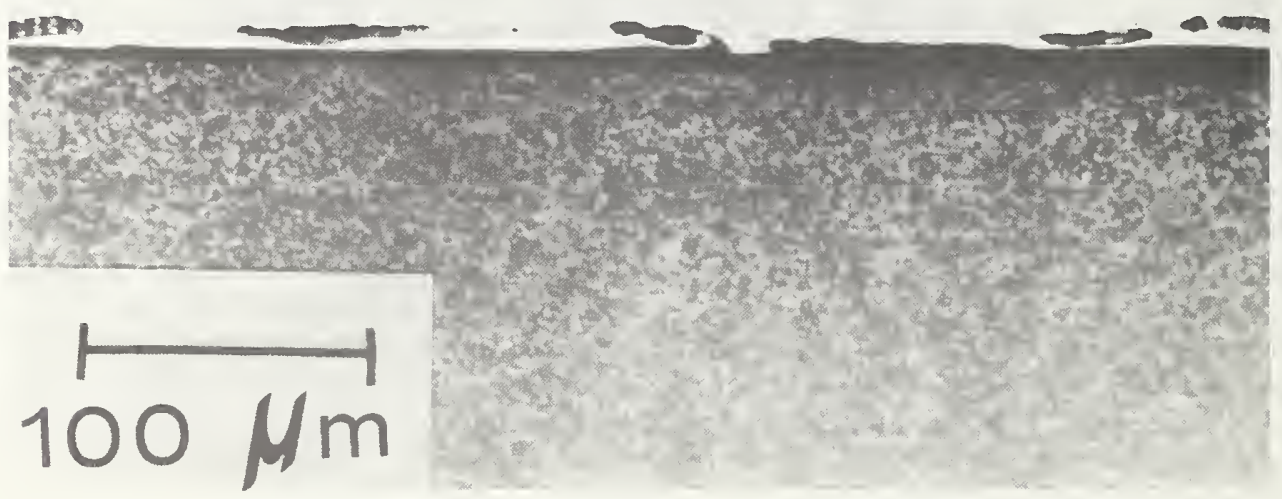

Figure 16. Photomicrograph showing a longitudinal cross-section of a BeO-Ta sheath assembly after vacuum degassing at temperatures to $1300 \mathrm{~K}$. Note the pores along the inner surface of the Ta sheath. 


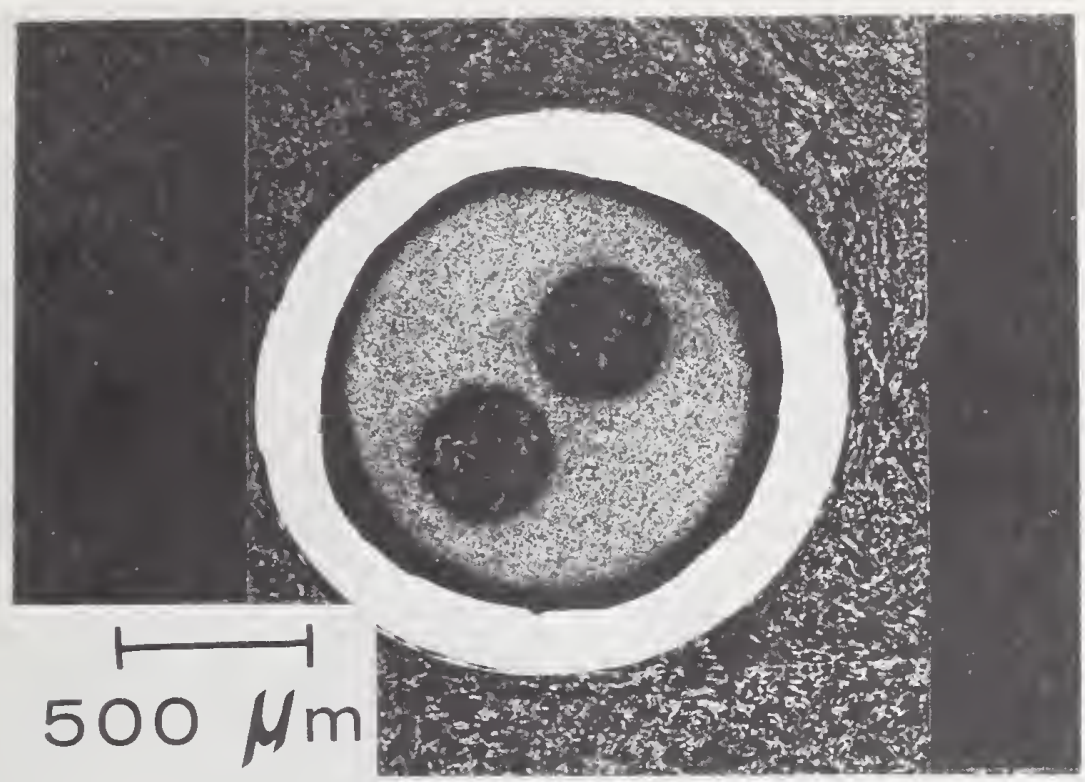

(a)

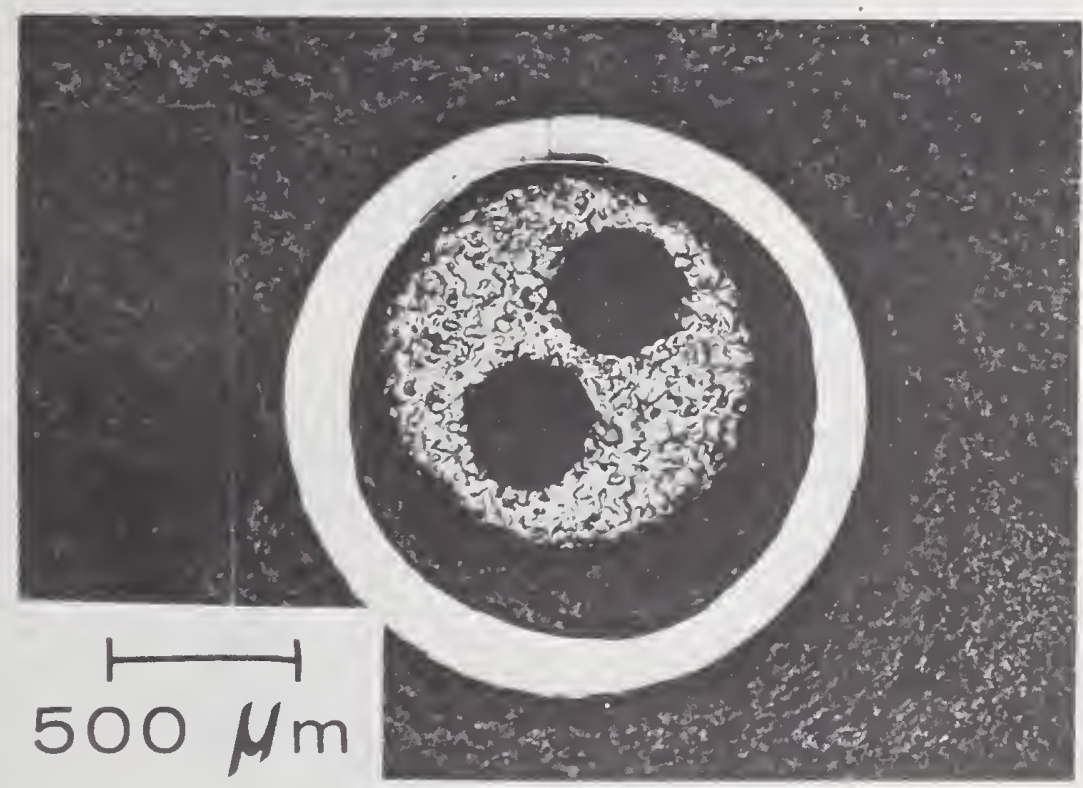

(b)

Flgure 17. Photomicrographs showing transverse cross-sections of BeO-Ta sheath assemblies (a) after vacuum degassing at temperatures to $1300 \mathrm{~K}$, and (b) after exposure for 50 hours at $2073 \mathrm{~K}$ in argon. The cross-sections were taken at about $4 \mathrm{~cm}$ below the open end of the sheath. 
In contrast, the $\mathrm{BeO}$ exposed at $2400 \mathrm{~K}$ exhibited a number of gross, detrimental effects. At the open end of the sheath, substantial erosion of the BeO insulators occurred. In assemblies exposed for 50 hours, a 50\% reduction in the insulator diameter in the region where it exited from the sheath was typical. This reduction was confined to a region a few millimeters in length. One sample of BeO insulator removed from the sheath also exhibited a longitudinal channel approximately $0.08 \mathrm{~mm}$ deep by $0.15 \mathrm{~mm}$ wide that extended the entire length of the insulator. A black deposit with a metallic appearance could be observed on both sides of the channel. In Ta-BeO assemblies exposed for 307 hours at $2400 \mathrm{~K}$, the BeO insulator was eroded away completely at the open end of the sheath and the end of the insulator had a conical shape. Gross erosion of the insulator was apparent at depths of 1 to $2 \mathrm{~cm}$ inside the sheath. A typical photomicrograph of one of the Ta sheath-BeO assemblies exhibiting a transverse cross-section $4_{4} \mathrm{~cm}$ below the open end of the sheath is shown in Fig. 18. Large cracks in the BeO insulator and erosion of the BeO are evident. While very little erosion of the BeO insulator was detected in assemblies exposed for 50 hours at $2250 \mathrm{~K}$, assemblies exposed for 1100 hours at this temperature showed substantial erosion of the insulator in the region where it exited from the sheath. A 70 to $80 \%$ reduction in the diameter of the insulator was observed in this region.

The tests at $2400 \mathrm{~K}$ were above the BeO phase transformation temperature of $2320 \mathrm{~K}$ (ref. 11). With the phase change, a large anomalous thermal expansion occurs, and the cracking of the dense, polycrystalline $\mathrm{BeO}$ in these tests is not surprising. The loss of $\mathrm{BeO}$ in the tests at 2250 and $2400 \mathrm{~K}$ might be explained by a number of different circumstances. However, if we assume that the observed material transport results only from reactions between $\mathrm{Ta}$ and $\mathrm{BeO}$, the conclusions as to what is happening are entirely reasonable, as taken from a discussion by Droege, et al., (ref. 12). They employed thermodynamic considerations to deduce the chemical compatibility of high temperature ceramic oxides with several refractory metals. If the reaction products of BeO with $\mathrm{Ta}$ are confined including the diffusion of oxygen through the Ta sheath, the system is stable and very little reaction will take place. Near the open end of the sheath, the gaseous reaction products experience very little confinement, so that rapid loss of gaseous Be, gaseous tantalum oxides and perhaps some oxygen occurs. Using the data of Droege et al., at $2400 \mathrm{~K}$ the partial pressure of $\mathrm{Be}(\mathrm{g})$ under equilibrium conditions of BeO with $\mathrm{Ta}$ is $8 \times 10^{-5}$ atm ( $6 \times 10^{-2}$ torr). Thus the rapid loss of BeO is not surprising, even under a cover gas of 1 atm of argon. Well inside the sheath, the reaction products are relatively confined, so that quasi-equilibrium conditions are partially established, and thus the rate of loss of $\mathrm{BeO}$ is greatly reduced.

\section{CONCLUDING REMARKS}

This report has presented studies of the effects of high temperature exposure on the component materials and on the completed assemblies of Ta-sheathed, BeO-insulated $\mathrm{W}-3 \%$ $\mathrm{Re} / \mathrm{W}-25 \%$ Re thermocouples. The exposures were in a high purity argon or helium environment. Some of the principal results follow.

\section{BeO-Ta COMPATIBILITY TESTS.}

Tests were performed at 2073,2250 and $2400 \mathrm{~K}$ for 50 hours, for 1100 hours at $2250 \mathrm{~K}$ and for 307 hours at $2400 \mathrm{~K}$. No gross physical changes in the tantalum sheaths were observed after the exposures (no tests were performed to detect changes in chemical purity). In the BeO, gross deleterious effects were observed in those samples exposed at $2400 \mathrm{~K}$. Erosion of the BeO insulators was substantial. Typically greater than $50 \%$ of the BeO insulator was eroded at the top of the sheath. Erosion was markedly less inside of the sheath, where the gaseous reaction products were partially confined. With exposure at $2400 \mathrm{~K}$, micro-cracking of the $\mathrm{BeO}$ occurred since the phase transformation temperature was exceeded. Serious problems with the BeO were not apparent at 2073 and $2250 \mathrm{~K}$ af ter 50 hours of exposure. At these temperatures the BeO insulators exhibited essentially only shrinkage (about $10 \%$ in diameter) that resulted from the further densification of the sintered BeO. Longer exposure ( 1100 hours) at $2250 \mathrm{~K}$ resulted in erosion of the BeO at the open end of the sheath. It was clear from these tests that BeO cannot be used reliably for long times in the presence of tantalum at temperatures above about $2100 \mathrm{~K}$, 


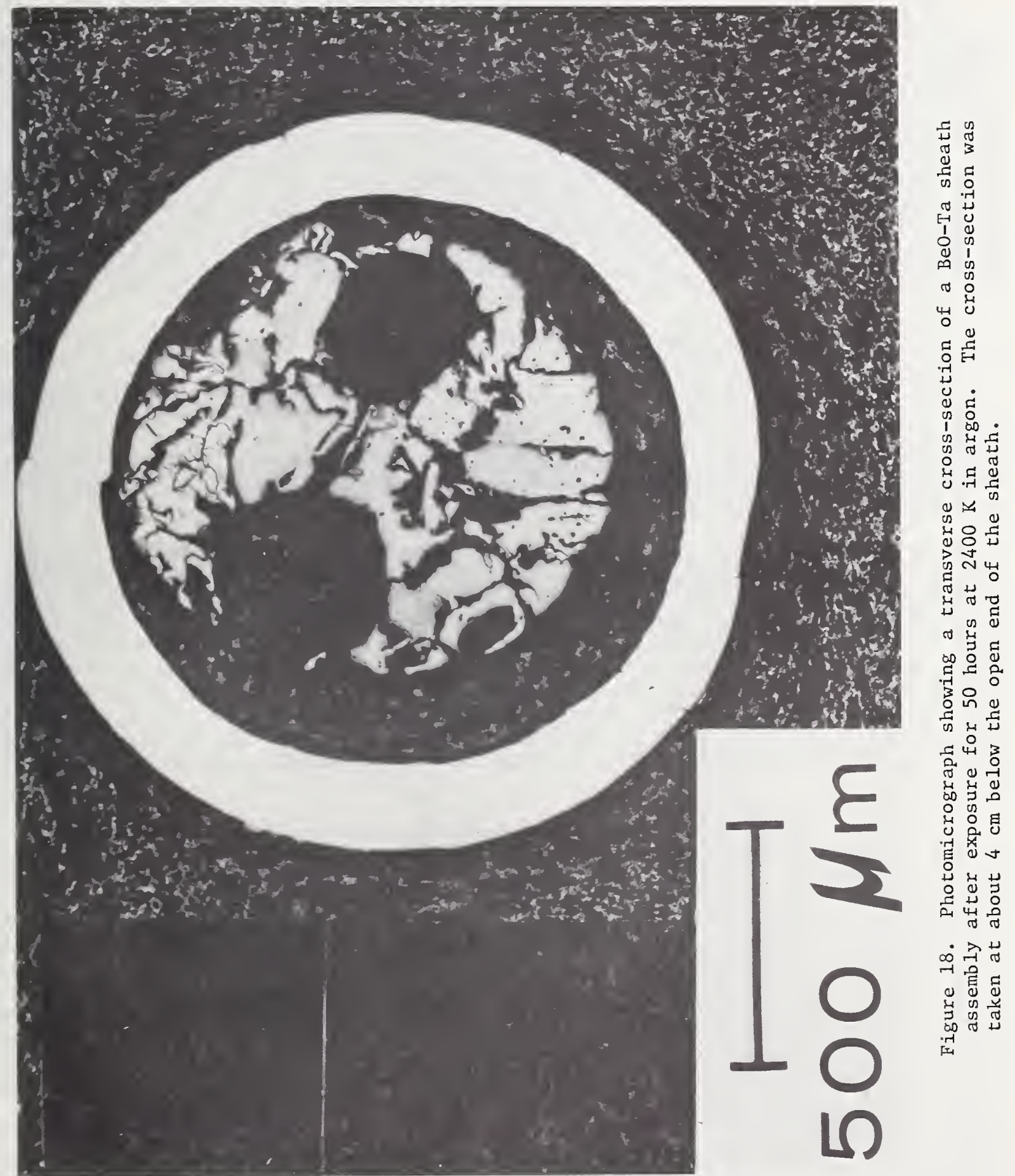


if the gaseous reaction products are not well confined.

\section{TESTS WITH UNSHEATHED, BeO-INSULATED THERMOCOUPLES}

Drift tests with BeO-insulated $\mathrm{W}-3 \% \mathrm{Re} / \mathrm{W}-25 \%$ Re thermocouples were performed in argon at $2250 \mathrm{~K}$ for 1100 hours and at $2400 \mathrm{~K}$ for 307 hours. The thermocouples in both tests exhibited a positive change in the thermal emf that was small, typically ranging from the equivalent of a few degrees $\mathrm{K}$ up to $+11 \mathrm{~K}$. Nevertheless, undesirable material degradation and interaction effects were observed in both tests, with the effects much greater at $2400 \mathrm{~K}$. In the hot zone of the furnace, the BeO insulators were eroded and reduced by the $\mathrm{Ta}$; a deposit that was later identified as Be coated the outside of the BeO insulators in the region of the furnace temperature gradient. At $2400 \mathrm{~K}$, the erosion was sufficient to bare the $\mathrm{W}-3 \%$ Re thermoelement and the thermoelement exhibited a $50 \mu \mathrm{m}$ thick coating of Ta. In addition, those portions of the insulator above the phase transformation temperature exhibited microcracking. Comparison with the results of the Ta-BeO compatability tests suggest that somewhat better material performance may be expected at these temperatures if the insulated thermocouples are encased and sealed hermetically within a Ta sheath.

\section{TESTS WITH SHEATHED THERMOCOUPLE ASSEMBLIES}

Four $1.6 \mathrm{~mm}$ diameter Ta sheathed, BeO insulated, $\mathrm{W}-3 \%$ Re versus $\mathrm{W}-25 \%$ Re thermocouple assemblies were constructed from aged thermoelements, heat-treated BeO insulators, and cleaned and etched Ta sheaths. The assemblies were checked to be gas tight (no indication of a leak when tested with a partial pressure analyzer) and were filled with high purity argon gas ( $1 \mathrm{~atm}$ at test temperature) for the test. The test exposed the thermocouple assemblies for $2059 \mathrm{~h}$ at $2073 \mathrm{~K}$ in helium (1 atm).

The four thermocouple assemblies exhibited virtually identical behavior during the test. The drift in the thermal emf was small and linear, varying from the equivalent of -0.3 to $-0.8 \mathrm{~K}$ per $1000 \mathrm{~h}$ of exposure at $2073 \mathrm{~K}$. The thermocouples were rapidly cooled to room temperature four times during the test (the cooling rate was about $400 \mathrm{~K} / \mathrm{min}$ for the first two minutes). The thermal cycling had no appreciable effect on the thermal emf at $2073 \mathrm{~K}$. After these coolings, calibrations of the thermocouples on reheating to the test temperature indicated that the drift in the thermal emf was also less than the equivalent of $-1 \mathrm{~K}$ per 1000 hours of exposure for calibration temperatures below $2073 \mathrm{~K}$. The changes in the thermal emf during the test (equivalent to less than $2 \mathrm{~K}$ ) were no larger than the systematic errors (estimated to be $1.9 \mathrm{~K}$ for measurements with the automatic photoelectric pyrometer).

At the conclusion of the test, the thermocouple assemblies were removed and dismantled. No gross chemical attack of the thermoelements, BeO insulators or the tantalum sheaths was apparent. Photomicrographs revealed the usual changes in structure observed in other tests (this report and refs, 1 and 4). Very large equiaxed grains (50 $\mu \mathrm{m}$ to one-half wire diameter in size) formed in the $\mathrm{W}-25 \%$ Re thermoelement. Densification of the $\mathrm{BeO}$ insulators that were exposed to high temperatures resulted in a $10 \%$ reduction in their diameter. This was accompanied by the formation of BeO grains of 30 to $90 \mu \mathrm{m}$ in size (compared to 1 to $5 \mu \mathrm{m}$ grain size in the starting material). In the region of the thermocouple assembly where the temperature rapidly fell towards ambient, a second phase at the grain boundaries of the $\mathrm{W}-25 \%$ Re thermoelement was observed, and was confined to the surface of the thermoelement $(<10 \mu \mathrm{m}$ depth). Spectrochemical analyses of sections of both $\mathrm{W}-3 \% \operatorname{Re}$ and $\mathrm{W}-25 \%$ Re thermoelements taken from this region indicated a small increase in the $\mathrm{Mg}$ and $\mathrm{Ca}$ impurity levels. In earlier work (ref. 1), sizeable reductions in the impurity levels of the BeO insulator were noted after exposure to high temperatures in the presence of tantalum. Chemical analyses of sections of tantalum sheath in this test indicated at least a ten-fold increase in $\mathrm{Al}, \mathrm{Ca}, \mathrm{Fe}, \mathrm{Mg}, \mathrm{Na}, \mathrm{Si}$, and $\mathrm{Ti}$, which were major residual impurities in the BeO tubing.

These tests results indicate that reliable, long term performance of Ta sheathed, BeO-insulated $\mathrm{W}-3 \%$ Re versus $\mathrm{W}-25 \%$ Re thermocouple assemblies can be obtained for thousands of hours with exposure at temperatures of 2000 to $2100 \mathrm{~K}$ in high purity gaseous environ- 
ments. Careful selection, heat treatment, and handling of materials were employed in these investigations. It is possible that the material specifications and construction techniques that were used may be more stringent than that which is required. Nevertheless, those who would desire to obtain thermocouple assemblies that perform reliably at these temperatures can be furnished with guidelines for their construction.

The $\mathrm{W}-3 \% \operatorname{Re}$ and $\mathrm{W}-25 \%$ Re thermoelements used in this investigation are available commercially. The thermoelements were given a special surface cleaning treatment by the supplier in order to more thoroughly remove surface contaminants introduced during the wire manufacturing process. The cleaning treatment included ultrasonic degreasing, abrading, and electro-etching. At NBS, the thermoelements were given an additional cleaning with ether. All materials were handled using clean plastic gloves and specially cleaned tools. Tests were performed on samples taken from the thermoelement wire lots to confirm that the emf-temperature relationship of the "as received" thermocouples from the matched lot complied with the suppliers calibration table to within the equivalent of $\pm 1 \%$ of the temperature. The thermoelements were degassed in vacuum ( $<5 \times 10^{-8}$ torr) for about 1 hour at $1570 \mathrm{~K}$, and then aged in argon at $2400 \mathrm{~K}$ for 1 hour ( $\mathrm{W}-3 \% \operatorname{Re}$ ) or 10 minutes ( $\mathrm{W}-25 \% \operatorname{Re})$ in order to essentially remove the initial emf shift. Recently obtained thermoelements may exhibit only minimal shifts (ref, 8), and aging of these thermoelements may not be required.

The sintered double-bore BeO insulators were in excess of $99.8 \%$ purity. They were given a preparatory vacuum ( $<5 \times 10^{-7}$ tor $r$ ) degassing at temperatures up to $1700 \mathrm{~K}$ over a 24 hour period. The degassing removed sorbed gases and also was effective in reducing some of the metallic impurity levels (ref. 1).

Tantalum tubing of greater than $99.97 \%$ purity was employed for the sheath. Degreasing and then etching was performed in order to remove surface contaminants, which are particularly difficult to remove on the inner wall of the tubing. The tubing was then degassed in vacuum ( $<5 \times 10^{-7}$ torr) at temperatures up to $2175 \mathrm{~K}$.

Fabrication of the thermocouple assemblies was performed in air. The assemblies were evacuated ( $<1 \times 10^{-8}$ torr) and tested for leaks with a partial pressure analyzer. The evacuated assemblies were then degassed at temperatures up to $1325 \mathrm{~K}$ to remove residual gas impurities, and back-filled with high purity argon gas (less than $10 \mathrm{ppm}$ total impurities). 
1. Burns, G. W. and Hurst, W. S.: Some Studies on the Behavior of W-Re Thermocouple Materials at High Temperatures. National Bureau of Standards (NASA CR-72884), Feb. 1972 .

2. Burns, G. W. and Hurst, W. S.: A Program in Refractory Metal Thermocouple Research. J. Research Nat1. Bur. Standards Vol. 75C, No. 2, April-June 1971, pp. 99-106.

3. Burns, G. W. and Hurst, W. S.: studies of the Performance of W-Re Type Thermocouples. Temperature, Vo1. 4, Part 3, (Instrument Society of America, Pittsburgh, 1972), pp. $1751-1766$.

4. Burns, G. W. and Hurst, W. S.: An Investigation of W-3\% Re and W-25\% Re Thermoelements in Vacuum, Argon and Hydrogen. National Bureau of Standards (NASA CR-72639)

March 10,1970 .

5. Devos, J. C.: Evaluation of the Quality of a Blackbody. Physica, Vol. Xx, No. 10, 0ct. 1954, pp. 669-689.

6. Toenshoff, D. A., Zysk, E. D., and Fleischner, P. L.: High Temperature Thermocouple Development Program. Engelhard Industries Division, Final Report, Contract NAS 3-10950 (NASA CR-120898), Oct. 1972.

7. Pugh, J. W., Amra, L. H., and Hurd, D. T.: Properties of Tungsten-Rhenium Lamp Wire. Trans. Am. Soc. Metals, Vol. 55, No. 3, Sept. 1962, pp. 451-461.

8. Tseng, Y.,.Schnatz, S., and Zysk, E. D.: Tungsten 3 Rhenium vs Tungsten 25 Rhenium Thermocouple--Some Recent Developments. Engelhard Industries Technical Bulletin, Vol. XI, No. 1, June 1970, pp. 12-18.

9. Lee, R. D.: The NBS Photoelectric Pyrometer and Its Use in Realizing the International Practical Temperature Scale above $1063{ }^{\circ} \mathrm{C}$. Metrologia, Vol. 2, No. 4, Oct. 1966, pp. 150-162.

10. Heckelman, J. D. and Kozar, R. P.: Measured Drift of Irradiated and Unirradiated $\mathrm{W}-3 \% \operatorname{Re} / \mathrm{W} 25 \% \operatorname{Re}$ Thermocouples at a Nominal $2000 \mathrm{~K}$. Temperature, Vo1. 4, Part 3, (Instrument Society of America, Pittsburgh, 1972), pp. 1935-1949.

11. Ryshkewitch, E.: Beryllium Oxide Ceramics Processes, Properties and Applications. Air Force Materials Laboratory Technical Report AFML-TR-65-378, Wright-Patterson Air Force Base, Uhio, May 1966.

12. Droege, John W., et al.: Refractory-Metal Thermocouples in Nuclear and High-Temperature Applications. AEC Contract W-7405-eng-92, Report No. BMI-X-10246, Nov. 22, 1968. 
Aerojet-General Nucleonics (1)

San Ramon, California 94583

Aero Research Instrument Department (1) American Standard

9000 King Street

Franklin Park, Illinois 60131

Attention: Mr. J. Faul

Aeronautical Systems Division (I) ASRMFP-2

Wright-Patterson Air Force Base

Dayton, Ohio 45433

Air Force Cambridge Research Center (1)

(CRZAP)

L.G. Hanscom Field

Bedford, Massachusetts 01730

Argonne National Laboratory (3)

9500 South Cass Avenue

Argonne, Illinois 60439

Attention: Mr. G. F. Popper

$\mathrm{Mr}$. A. E. Knox

Mr. C. Williams

Battelle Memorial Institute (2)

505 King Avenue

Columbus, Ohio 43201

Attention: Dr. J. Droege

Mr. D. Treweek

The Boeing Company (1)

P. O. Box 3999

Seattle, Washington 98124

Attention: Aerospace Library 8K38

Brookhaven National Laboratory (1)

Associated Universities, Inc.

Upton, Long Island, New York 11973

Brush Wellman, Inc. (1)

Elmore, Ohio 43416

Attention: Mr. J. W. Duncan

Cleveland Refractory Metals ( 1 )

28850 Aurora Road

Solon, Ohio 44139

Attention: Mr. H. Stephens

Office of Technical Services (I)

Department of Commerce

Washington, D.C. 20230

Consolidated Controls Corporation (1)

6 Durant Avenue

Bethel, Connecticut 06801
Director Advanced Research Projects Agency (1)

The Pentagon

Washington, D.C. 20525

Engelhard Minerals and Chemicals Corp. (2)

Research Center

Menlo Park

Edison, New Jersey 08817

Attention: Mr. E. D. Zysk

Mr. D. A. Toenshoff

Electro-Optical Systems, Inc. (I)

300 North Halstead Street

Pasadena, California 91104

General Atomic Company (8)

P. 0. Box 61608

San Diego, California 92138

Attention: Dr. L. Yank

Mr. F. Carpenter

Mr. N. Sandefur

Dr. D. E. Schwarzer

Mr. J. Steibel

Mr. R. Grenda

Mr. G. Graeber

Mr. R. Dalry

General Electric Company (2)

Vallecitos Nuclear Center

Pleasanton, California 94566

Attention: Dr. J. C. Danko

Mr. J. Case

General Electric Company

Cincinnati, Ohio 45215

Attention: Mr. W. C. Kuhlman

Mr. W. G. Baxter

General Electric Company ( 1 )

West Lynn, Massachusetts 01905

Attention: Mr. R. B. Clark

Genera1 Electric Company

21800 Tungsten Road

Cleveland, Ohio 44117

Attention: Dr. T. Dunham

General Electric Research Laboratory (1)

Schenectady, New York 11501

Attention: Dr. V. C. Wilson

General Telephone and Electronics Labs, Inc. (I) Bayside, New York 11061 
Hanford Engineering Development Laboratory Westinghouse Hanford Company Richland, Washington 55901

Attention: Dr. R. R. Schemmel

Dr. E. T. Weber

Mr. D. C. Kaulitz

Hoskins Manufacturing Company

4445 Lawton Avenue

Detroit, Michigan 48208

Attention: Mr. N. Spooner

Mr. F. Sibley

Mr. T. Verlinde

Hughes Research Laboratories (1)

3011 Malibu Canyon Road

Malibu, California 90265

Attention: Dr. R. C. Knechlti

McDonnel1 Douglas Corporation (1)

Department 257, Building 102

Mail Stop 275

St. Louis, Missouri 63166

Attention: Mr. R. Bumby

Metallurgy Division (1)

Building 393.7

AERE Harwel1

Didcot

Berks, England

Attention: Dr. O. S. Plail

North American-Rockwel1 (2)

Atomics International

8900 Desoto Avenue

Canoga Park, California 91304

Attention: Mrs. M. Gerber

Mr. E. L. Babbe

Process Technology Division (1)

Building 220.22

AERE Harwel1

Didcot

Berks, England

Attention: Mr. P. Marden

Jet Propulsion Laboratory (1)

California Institute of Technology

4800 Oak Grove Drive

Pasadena, California 91103

Attention: Mr. R. S. Caputo

Lawrence Radiation Laboratory (1)

University of California

Berkeley, California 94704

Attention: Library
(3) Los Alamos Scientific Laboratory (3)

P. 0. Box 1663

Los Alamos, New Mexico 87544

Attention: Mr. C. R. Tallman

Mr. R. J. Fries

$\mathrm{Mr}$. B. G. Goodier

The Marquardt Corporation (1)

ASTRO Division

16555 Saticoy Street

Van Nuys, California 91409

National Aeronautics \& Space Admin. (1)

$1520 \mathrm{H}$ Street, N.W.

Washington, D.C. 20005

Attention: Mr. J. J. Lynch

National Aeronautics \& Space Admin. (1)

Marshall Space Flight Center

Huntsville, Alabama 35812

Attention: Library

National Aeronautics \& Space Admin.

Langley Research Center

Langley Field, Virginia 23365

Attention: Library

National Aeronautics \& Space Admin. (1)

Goddard Space Flight Center

Greenbelt, Maryland 20771

Attention: Library

National Aeronautics \& Space Admin. (1) Ames Research Center

Moffett Field, California 94035

Attention: Library

National Aeronautics \& Space Admin. (39)

Lewis Research Center

21000 Brookpark Road

Cleveland, Ohio 44135

Attention: B. Lubarsky

J. E. Dilley

MS 3-3

L. Rosenblum

MS 500-309

I. Warshawski

MS 302-1

G. E. Glawe

MS 77-1

J. W. Breagh

MS 77-1

Library

MS 49-2

Report Control Office MS 5-5

Technology Utilization

$$
\text { Office }
$$

MS 3-19

R. H. Titran

MS $105-1$

V. F. Hlavin

MS $3-14$

National Beryllia Corporation (1)

Greenwood Avenue

Haskell, New Jersey 07420

Attention: Dr. P. L. Fleischner 
National Bureau of Standards

Washington, D.C. 20234

Attention: Mr. C. H. Brady

Dr. D. L. Vieth

Dr. D. H. Reneker

Mr. P. D. Freeze

Dr. K. L. Churney

Dr. H. J. Kostkowski

Office of Technical Information

Library

Oak Ridge National Laboratory

P. O. Box X

Oak Ridge, Tennessee 37830

Attention: Mr. R. L. Sheppard

Dr. D. L. McElroy

Library

Dr. R. L. Anderson

Dr. R. K. Williams

Naval Research Laboratory

Washington, D.C. 20390

Attention: R. Spann

C. T. Ewing

Technical Information Div.

Power Information Center (1)

3401 Market Street, Room 2207

Philadelphia, Pennsylvania 19104

Pratt and Whitney Aircraft (2)

400 Main Street

East Hartford, Connecticut 06108

Attention: $\mathrm{Mr}$. P. Bliss

Mr. T. M. Anderson

The Rand Corporation (1)

1700 Main Street

Santa Monica, California 90401

Republic Aviation (2)

Farmindale

Long Island, New York 11735

Attention: Mr. A. Schock

Mr. B. Walk
Stellite Division (1)

Cabot Corporation

Div. 312.01 3705 Redbud Lane

Div. 310.02 Kokomo, Indiana 46901

Div. 311.03 Attention: Dr. R. L. Wagner

Div. 425.03

Div. 316.01 Texas Instruments, Inc. (1)

Div. 221.12 P. O. Box 5474

Div. 153.00

Div. 154.00 Thermo Electron Corporation (1)

85 First Avenue

Waltham, Massachusetts 02154

Attention: Dr. G. Hatsopoulos

Thomson Ramo Wooldrige, Inc. (1)

7209 Platt Avenue

Cleveland, Ohio 44104

Attention: Mr. W. L. Leoric

United States Atomic Energy Comm (1)

Department of Technical Information Extension

P. 0. Box 62

Oak Ridge, Tennessee 37831

Westinghouse Electric Corporation (1) Waltz Mill Site

P. O. Box 158

Madison, Pennsylvania 15663

Attention: Mr. G. A. Remley

Westinghouse Electric Corporation (1)

Research Laboratories

Beulah Road, Churchilboro

Pittsburgh, Pennsylvania 15235

Attention: Dr. Garbuny

Scientific Engineering and Manufacturing Co., Inc. (1)

11505 Vanowen Street

North Hollywood, California 91605

Attention: Library

Special Technology Branch (1)

DRDT

AEC Headquarters

Washington, D.C. 20545

Attention: Mr. F. C. Legler 



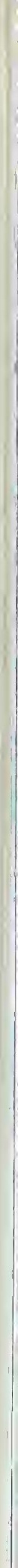




